$1 N-26$

NASA Technical Memorandum 110307

d 150

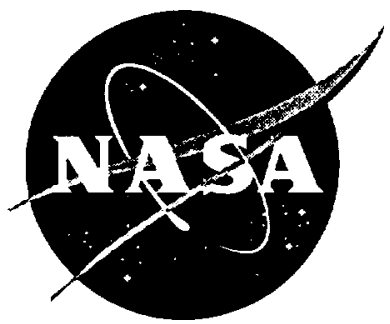

\title{
Fatigue-Life Prediction Methodology Using Small-Crack Theory
}

J. C. Newman, Jr. and E. P. Phillips

Langley Research Center, Hampton, Virginia

M. H. Swain

Lockheed Martin Engineering and Sciences, Hampton, Virginia

January 1997

National Aeronautics and

Space Administration

Langley Research Center

Hampton, Virginia 23681-0001 
FATIGUE-LIFE PREDICTION METHODOLOGY USING SMALL-CRACK THEORY

\author{
J. C. Newman, Jr. and E. P. Phillips \\ NASA Langley Research Center \\ Hampton, Virginia, USA \\ M. H. Swain \\ Lockheed Martin Engineering and Sciences \\ Hampton, Virginia, USA
}

\begin{abstract}
This paper reviews the capabilities of a plasticity-induced crack-closure model to predict fatigue lives of metallic materials using "small-crack theory" for various materials and loading conditions. Crack-tip constraint factors, to account for three-dimensional state-of-stress effects, were selected to correlate large-crack growth rate data as a function of the effective-stressintensity factor range ( $\Delta \mathrm{K}_{\mathrm{eff}}$ ) under constant-amplitude loading. Some modifications to the $\Delta \mathrm{K}_{\mathrm{eff}}$ -rate relations were needed in the near-threshold regime to fit measured small-crack growth rate behavior and fatigue endurance limits. The model was then used to calculate small- and largecrack growth rates, and to predict total fatigue lives, for notched and un-notched specimens made of two aluminum alloys and a steel under constant-amplitude and spectrum loading. Fatigue lives were calculated using the crack-growth relations and microstructural features like those that initiated cracks for the aluminum alloys and steel for edge-notched specimens. An equivalentinitial-flaw-size concept was used to calculate fatigue lives in other cases. Results from the tests and analyses agreed well.
\end{abstract}

\title{
NOMENCLATURE
}

a Crack length in thickness (B) direction, $\mathrm{mm}$

$\mathrm{a}_{\mathbf{i}} \quad$ Initial defect or crack length in B-direction, $\mathrm{mm}$

b Defect or void half-height, $\mathrm{mm}$

B Specimen thickness, $\mathrm{mm}$

c Crack length in width (w) direction, $\mathrm{mm}$

$c_{i} \quad$ Initial defect or crack length in w-direction, $\mathrm{mm}$ 


\begin{tabular}{|c|c|}
\hline $\mathbf{F}$ & Boundary-correction factor \\
\hline $\mathbf{K}_{\mathbf{F}}$ & Elastic-plastic fracture toughness in TPFC, $\mathrm{MPa} / \mathrm{m}$ \\
\hline m & Fracture toughness parameter in TPFC \\
\hline $\mathbf{N}$ & Number of cycles \\
\hline $\mathbf{N}_{\mathbf{f}}$ & Number of cycles to failure \\
\hline $\mathbf{R}$ & Stress ratio $\left(\mathrm{S}_{\min } / \mathrm{S}_{\max }\right)$ \\
\hline $\mathbf{r}$ & Notch or hole radius, $\mathrm{mm}$ \\
\hline $\mathbf{S}$ & Applied stress, MPa \\
\hline$S_{0}^{\prime}$ & Crack-opening stress, MPa \\
\hline$S_{\max }$ & Maximum applied stress, $\mathrm{MPa}$ \\
\hline$S_{\min }$ & Minimum applied stress, $\mathrm{MPa}$ \\
\hline $\mathbf{w}$ & Specimen width or half-width (see Fig. 2), mm \\
\hline$\alpha$ & Constraint factor \\
\hline$\Delta \mathbf{K}$ & Stress-intensity factor range, $\mathrm{MPa} / \mathrm{m}$ \\
\hline$\Delta \mathrm{K}_{\mathrm{eff}}$ & Effective stress-intensity factor range, $\mathrm{MPa} / \mathrm{m}$ \\
\hline$\left(\Delta \mathrm{K}_{\mathrm{eff}}\right)_{\mathrm{T}}$ & Effective stress-intensity factor range, $\mathrm{MPa} \sqrt{\mathrm{m}}$ \\
\hline$\left(\Delta K_{\text {eff }}\right)_{\text {th }}$ & Small crack $\Delta \mathrm{K}_{\text {eff }}$ threshold, $\mathrm{MPa} \sqrt{\mathrm{m}}$ \\
\hline$\Delta \mathbf{K}_{\text {th }}$ & Large crack $\Delta \mathrm{K}$ threshold, $\mathrm{MPa} / \mathrm{m}$ \\
\hline $\boldsymbol{\rho}$ & Plastic-zone size, mm \\
\hline$\sigma_{\mathbf{o}}$ & Flow stress (average of $\sigma_{y s}$ and $\sigma_{u}$ ), MPa \\
\hline$\alpha_{y s}$ & Yield stress ( 0.2 percent offset), $\mathrm{MPa}$ \\
\hline$\sigma_{u}$ & Ultimate tensile strength, $\mathrm{MPa}$ \\
\hline $\boldsymbol{\omega}$ & Cyclic-plastic-zone size, $\mathrm{mm}$ \\
\hline
\end{tabular}

\section{INTRODUCTION}

On the basis of linear-elastic fracture mechanics (LEFM), studies on small cracks (10 $\mu \mathrm{m}$ to $1 \mathrm{~mm}$ ) have shown that small cracks grow much faster than would be predicted from large crack data (Pearson [1]; Ritchie and Lankford [2]; Miller and de los Rios [3]). This behavior is illustrated in Figure 1, where the crack-growth rate, $d a / d N$ or $d c / d N$, is plotted against the linearelastic stress-intensity factor range, $\Delta \mathbf{K}$. The solid (sigmoidal) curve shows typical results for large cracks in a given material and environment under constant-amplitude loading. The solid curve is usually obtained from tests with large cracks. At low growth rates, the threshold stress- 


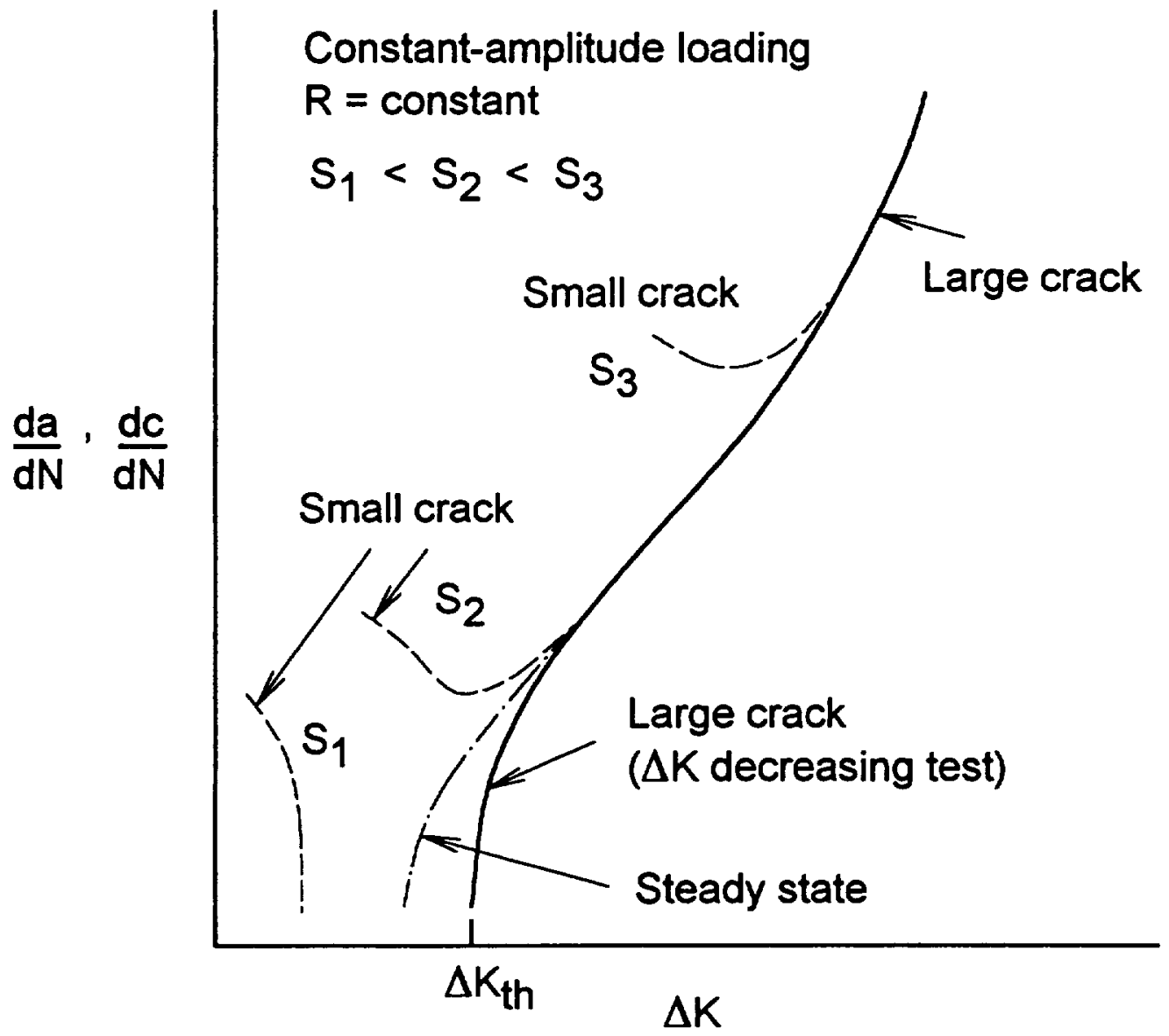

Figure 1. Typical fatigue-crack-growth behavior for small and large cracks.

intensity factor range, $\Delta K_{\text {th }}$ is usually obtained from load-reduction ( $\Delta K$-decreasing) tests. Some typical results for small cracks in plates and at notches are shown by the dashed curves. These results show that small cracks grow at $\Delta K$ levels below the large-crack threshold and that they also grow faster than large cracks at the same $\Delta \mathrm{K}$ level above threshold. Small-crack effects have been shown to be more prevalent in tests which have compressive loads, such as negative stress ratios (Zocher [4], Newman and Edwards [5,6]). Over the past decade, various studies on smallor short-crack growth behavior in metallic materials have led to the realization that fatigue life of many materials is primarily "crack growth" from microstructural features, such as inclusion particles, voids or slip-band formation. Concurrently, improved fracture-mechanics analyses of some of the crack-tip shielding mechanisms, such as plasticity-induced crack closure, and analyses 
of surface- or corner-crack configurations (Raju and Newman [7,8]) have led to more accurate crack growth and fatigue-life prediction methods. Thus, "small-crack theory" is the treatment of fatigue as a crack-propagation process from a micro-defect (or crack) to failure.

During the last decade, research on small- or short-crack effects have concentrated on three possible explanations for the behavior of such cracks. They are plasticity effects, metallurgical effects, and crack closure. All of these features contribute to an inadequacy of LEFM and the use of the $\Delta K$-concept to correlate fatigue crack growth rates. Some of the earliest small-crack experiments were conducted at high stress levels which were expected to invalidate LEFM methods. Nonlinear or elastic-plastic fracture mechanics concepts, such as the J-integral and an empirical length parameter (El Haddad et al. [9]), were developed to explain the observed smallcrack effects. Recent research on the use of $\Delta \mathrm{J}$ as a crack-driving parameter suggest that plasticity effects are small for many of the early and more recent small-crack experiments (Newman [10]). But the influence of plasticity on small-crack growth and the appropriate crackdriving parameter is still being debated.

Small cracks tend to initiate in metallic materials at inclusion particles or voids, in regions of intense slip, or at weak interfaces and grains. In these cases, metallurgical similitude breaks down for these cracks (which means that the growth rate is no longer an average taken over many grains), see Leis et al. [11]. Thus, the local crack growth behavior is controlled by metallurgical features. If the material is markedly anisotropic, the local grain orientation will strongly influence the growth rate. Crack-front irregularities and small particles or inclusions affect the local stresses and, therefore, the crack growth response. For large cracks, all of these metallurgical effects are averaged over many grains, except in very coarse-grained materials. LEFM and nonlinear fracture mechanics concepts are only beginning to explore the influence of metallurgical features on stress-intensity factors, strain-energy densities, J-integrals and other crack-driving parameters.

Very early in small-crack research, fatigue-crack closure (Elber [12]) was recognized as a possible explanation for rapid small-crack growth rates (see Nisitani and Takao [13]). Fatigue crack closure is caused by residual plastic deformations left in the wake of an advancing crack. Only that portion of the load cycle for which the crack is fully open is used in computing an effective stress-intensity factor range ( $\left.\Delta \mathrm{K}_{\text {eff }}\right)$ from LEFM solutions. A small crack initiating at an inclusion particle, a void or a weak grain does not have the prior plastic history to develop closure. Thus, a small crack may not be closed for as much of the loading cycle as a larger crack. 
If a small crack is fully open, the stress-intensity factor range is fully effective and the crackgrowth rate will be greater than steady-state crack-growth rates. (A steady-state crack is one in which the residual plastic deformations and crack closure along the crack surfaces are fully developed and stabilized under steady-state loading.) Small-crack growth rates are also faster than steady-state behavior because these cracks may initiate and grow in weak microstructure. In contrast to small-crack growth behavior, the development of the large-crack threshold, as illustrated in Figure 1, has also been associated with a rise in crack-opening load as the applied load is reduced (Minikawa and McEvily [14]; Newman [15]). Thus, the steady-state crackgrowth behavior may lie between the small-crack and large-crack threshold behavior, as illustrated by the dash-dot curve.

The purpose of this paper is to review the capabilities of a plasticity-induced crack-closure model (Newman $[16,17])$ to correlate large-crack growth rate behavior, and to predict fatigue lives, in two aluminum alloys and a steel under various load histories using small-crack theory. Test results from the literature on 2024-T3 and 7075-T6 aluminum alloys and 4340 steel under constant-amplitude loading were analyzed with the closure model to establish an effective stressintensity factor range ( $\Delta \mathrm{K}_{\text {eff }}$ ) against crack-growth rate relation. The $\Delta \mathrm{K}_{\text {eff }}$-rate relation and some micro-structural features were used with the closure model to predict total fatigue lives on notched specimens made of aluminum alloys and steel under various load histories. An equivalent-initial-flaw-size (EIFS) concept (Rudd et al. [18]) was used to calculate fatigue lives for un-notched aluminum alloys. The load histories considered were constant-amplitude loading over a wide range in stress ratios, FALSTAFF (van Dijk et al. [19]), Gaussian (Huck et al. [20]), TWIST (deJonge et al. [21]), Mini-TWIST (Lowak et al. [22]) and Felix/28 (Edwards and Darts [23]) load sequences. The crack configurations used in these analyses were middle-crack tension specimens, and three-dimensional crack configurations, such as a corner crack in a plate or a surface crack at a hole or semi-circular edge notch. Comparisons are made between measured and calculated or predicted fatigue lives on various un-notched and notched specimens.

\section{CRACK AND NOTCH CONFIGURATIONS ANALYZED}

The large-crack $\Delta K$-rate data for the two aluminum alloys and the steel were obtained from middle-crack tension specimens. The data for the 2024-T3 alloy was obtained from Hudson [24], Phillips [25], and Dubensky [26], whereas the data for the 7075-T6 alloy was obtained from 
Phillips and Deng (see Refs. 27 and 28). The data for the 4340 steel was obtained from Swain et al. [29].

The fatigue specimens analyzed are shown in Figure 2. They were: (a) the uniform stress $\left(\mathrm{K}_{\mathrm{T}}=1\right)$ un-notched specimen, (b) the circular-hole $\left(\mathrm{K}_{\mathrm{T}}=3\right)$ specimen, and (c) the single-edgenotch tension (SENT; $\mathrm{K}_{\mathrm{T}}=3.15$ or 3.3 ) specimen. Here the stress concentration factor, $\mathrm{K}_{\mathrm{T}}$, is expressed in term of remote (gross) stress, $\mathrm{S}$, instead of the net-section stress.
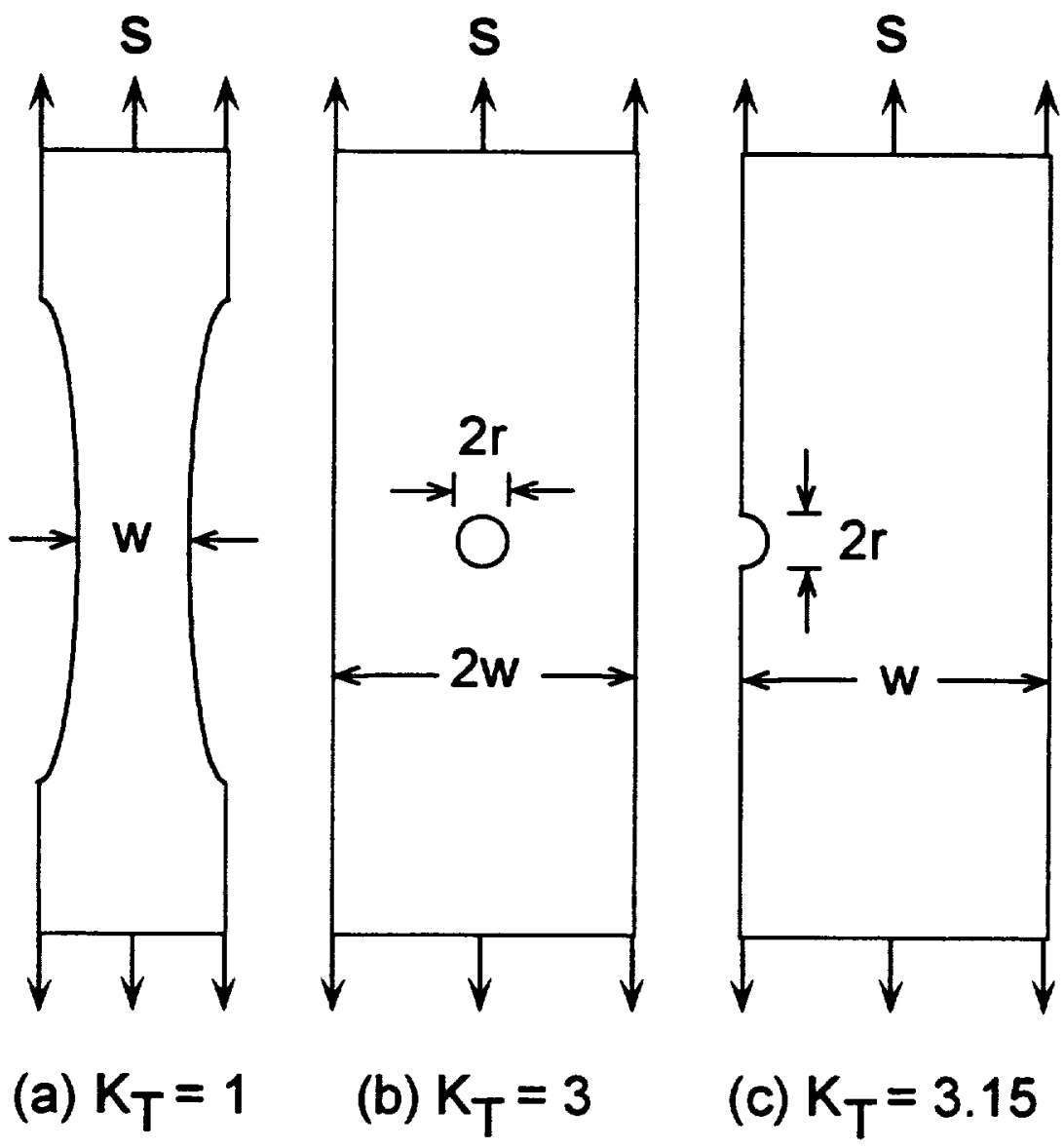

(b) $\mathrm{K}_{\mathrm{T}}=3$

(c) $\mathrm{K}_{\mathrm{T}}=3.15$

Figure 2. Fatigue specimens analyzed with "small-crack theory."

\section{PLASTICITY-INDUCED CRACK-CLOSURE MODEL}

The crack-closure model (Newman [16]) was developed for a central through crack in a finite-width specimen subjected to remote applied stress. The model was later extended to a through crack emanating from a circular hole and applied to the growth of small cracks (Newman [15]). The model was based on the Dugdale [30] model, but modified to leave plastically 
deformed material in the wake of the crack. The details of the model are given elsewhere and will not be presented here. One of the most important features of the model, however, is the ability to model three-dimensional constraint effects. A constraint factor, $\alpha$, is used to elevate the flow stress $\left(\alpha \sigma_{0}\right)$ at the crack tip to account for the influence of stress state. The flow stress $\sigma_{0}$ is the average between the yield stress and ultimate tensile strength. For plane-stress conditions, $\alpha$ is equal to unity (original Dugdale model); and for simulated plane-strain conditions, $\alpha$ is equal to 3 . Although the strip-yield model does not model the correct yield-zone pattern for plane-strain conditions, the model with a high constraint factor is able to produce crack-surface displacements and crack-opening stresses quite similar to those calculated from an elastic-plastic finite-element analysis of crack growth and closure for a finite-thickness plate (Blom et al. [31]). In conducting fatigue-crack growth analyses, the constraint factor $\alpha$ is used as a fitting parameter to correlate crack-growth rate data against $\Delta \mathrm{K}_{\text {eff }}$ under constant-amplitude loading for different stress ratios. However, tests conducted under single-spike overloads seem to be more sensitive to state-ofstress effects and may be a more appropriate test to determine the constraint factor.

\section{Effective Stress-Intensity Factor Range}

For most damage tolerance and durability analyses, the linear-elastic analyses have been found to be adequate. The linear-elastic effective stress-intensity factor range developed by Elber [12] is given by

$$
\Delta K_{\text {eff }}=\left(S_{\max }-S_{o}^{\prime}\right) \sqrt{ }(\pi c) F(c / w)
$$

where $S_{\max }$ is the maximum stress, $S_{0}{ }_{0}$ is the crack-opening stress and $F$ is the boundarycorrection factor. However, for high stress-intensity factors, proof testing, and low-cycle fatigue conditions, the linear-elastic analyses are inadequate and nonlinear crack-growth parameters are needed. To account for plasticity, a portion of the Dugdale cyclic-plastic-zone length $(\omega)$ has been added to the crack length, $c$. The cyclic-plastic-zone-corrected effective stress-intensity factor $[10]$ is

$$
\left(\Delta K_{p}\right)_{\text {eff }}=\left(S_{\max }-S_{o}^{\prime}\right) \sqrt{ }(\pi d) F(d / w)
$$

where $d=c+\omega / 4$ and $F$ is the cyclic-plastic-zone corrected boundary-correction factor. Herein, the cyclic-plastic-zone corrected effective stress-intensity factor range will be used in the fatiguelife predictions unless otherwise noted. 


\section{Constant-Amplitude Loading}

As a crack grows in a finite-thickness body under cyclic loading (constant stress range), the plastic-zone size at the crack front increases. At low stress-intensity factor levels, plane-strain conditions should prevail but as the plastic-zone size becomes large compared to sheet thickness, a loss of constraint is expected. This constraint loss has been associated with the transition from flat-to-slant crack growth. Schijve [32] has shown that the transition occurs at nearly the same crack-growth rate over a wide range in stress ratios for an aluminum alloy. This observation has been used to help select the constraint-loss regime (see Ref. 33).

Newman [17] developed crack-opening stress equations for constant-amplitude loading from crack-closure model calculations for a middle-crack tension specimen. These equations give crack opening stress as a function of stress ratio $(R)$, maximum stress level $\left(S_{\max } / \sigma_{0}\right)$ and the constraint factor $(\alpha)$. These equations are used to develop the baseline $\Delta \mathrm{K}_{\text {eff }}$-rate relations that are used in the life-prediction code FASTRAN-II [34] to make crack-growth and fatigue-life predictions.

\section{LARGE-CRACK GROWTH BEHAVIOR}

To make life predictions, $\Delta \mathrm{K}_{\text {eff }}$ as a function of the crack-growth rate must be obtained for the material of interest. Fatigue crack-growth rate data should be obtained over the widest possible range in rates (from threshold to fracture), especially if spectrum load predictions are required. Data obtained on the crack configuration of interest would be helpful but it is not essential. The use of the nonlinear crack-tip parameters is only necessary if severe loading (such as low cycle fatigue conditions) are of interest. Most damage-tolerant life calculations can be performed using the linear elastic stress-intensity factor analysis with crack-closure modifications.

Under constant-amplitude loading, the only unknown in the analysis is the constraint factor, $\alpha$. The constraint factor is determined by finding (by trial-and-error) an $\alpha$ value that will correlate the constant-amplitude fatigue-crack-growth-rate data over a wide range in stress ratios, as shown by Newman [17]. This correlation should produce a unique relationship between $\Delta K_{\text {eff }}$ and crack-growth rate. In the large-crack-growth threshold regime for some materials, the plasticity-induced closure model may not be able to collapse the threshold ( $\Delta \mathrm{K}$-rate) data onto a unique $\Delta \mathrm{K}_{\text {eff }}$-rate relation because of other forms of closure. Roughness- and oxide-induced closure (see Ritchie and Lankford [2]) appear to be more relevant in the threshold regime than plasticity-induced closure. This may help explain why the constraint factors needed to correlate 
crack-growth rate data in the near threshold regime are lower than plane-strain conditions. The constraint factors are 1.7 to 2 for aluminum alloys, 1.9 to 2.2 for titanium alloys and 2.5 for steel. However, further study is needed to assess the interactions between plasticity-, roughness- and oxide-induced closure in this regime. If the plasticity-induced closure model is not able to give a unique $\Delta K_{\text {eff }}$-rate relation in the threshold regime, then high stress ratio $(R \geq 0.7)$ data may be used to establish the $\Delta \mathrm{K}_{\text {eff }}$-rate relation.

In the following, the $\Delta \mathrm{K}_{\text {eff }}$-rate relation for two aluminum alloys and a steel will be presented and discussed. A detailed description will be given for one material but similar procedures were used to establish the relationships for all materials used in this study.

\section{Aluminum Alloy 2024-T3}

The large-crack results for 2024-T3 aluminum alloy are shown in Figure 3 for data generated by Hudson [24], Phillips [25] and Dubensky [26]. This figure shows the elastic $\Delta \mathrm{K}_{\text {eff }}$ (eqn. 1) plotted against crack-growth rate. The data collapsed into a narrow band with several transitions in slope occurring at about the same rate for all stress ratios. Some large differences were observed at high $\mathrm{R}$-ratios in the high-rate regime. These tests were conducted at extremely high remote stress levels ( 0.75 and 0.95 of the yield stress). Even elastic-plastic analyses, such as equation (2), were unable to collapse the data along a unique curve in this regime. From a highcycle fatigue standpoint, however, this discrepancy has very little influence on total life. The elastic-plastic fracture criterion (Two-Parameter Fracture Criterion, TPFC; see Ref. 36) used in the analysis $\left(\mathrm{K}_{\mathrm{F}}=267 \mathrm{MPa} \sqrt{\mathrm{m}} ; \mathrm{m}=1\right)$ predicted failure very near to the vertical asymptotes of the test data, see the vertical dashed and dotted lines for $R=0.7$ and 0.5 (at 0.75 and 0.95 of yield), respectively. Similar vertical lines (not shown) would also indicate failure at the other $R$

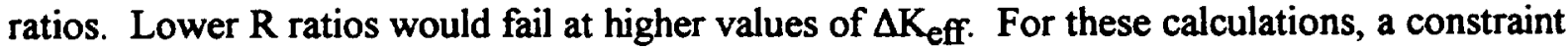
factor $(\alpha)$ of 2.0 was used for rates less than $1 E-07 \mathrm{~m} /$ cycle (start of transition from flat-to-slant crack growth) and $\alpha$ equal to 1.0 was used for rates greater than $2.5 \mathrm{E}-06 \mathrm{~m} / \mathrm{cycle}$ (end of transition from flat-to-slant crack growth). For intermediate rates, $\alpha$ was varied linearly with the logarithm of crack-growth rate (see Ref. 34). The values of $\alpha$ and rate were selected by trialand-error and from analyses of crack growth under spectrum loading (see Ref. 35). The constraint-loss regime ( $\alpha=2$ to 1 ) has also been associated with the flat-to-slant crack-growth behavior. Reference 35 developed an expression to predict the location of the flat-to-slant crackgrowth regime and the effective stress-intensity factor at transition is by 


$$
\left(\Delta \mathrm{K}_{\mathrm{eff}}\right)_{\mathrm{T}}=0.5 \sigma_{0} \sqrt{\mathrm{B}}
$$

For the 2024-T3 alloy sheet, $\left(\Delta \mathrm{K}_{\mathrm{eff}}\right)_{\mathrm{T}}=10.2 \mathrm{MPa} \mathrm{Vm}$. The width of the constraint-loss regime, in terms of rate or $\Delta \mathrm{K}_{\mathrm{eff}}$, is a function of thickness but this relationship has yet to be developed. In the low crack-growth rate regime, near and at threshold, tests and analyses $[14,15]$ have indicated that the threshold develops because of a rise in the crack-opening-stress-to-maximum-stress ratio due to the load-shedding procedure. In the threshold regime then, the actual $\Delta \mathrm{K}_{\mathrm{eff}}$-rate data would lie at lower values of $\Delta \mathrm{K}_{\mathrm{eff}}$ because the rise in crack-opening stress was not accounted for in the current analysis. For the present study, an estimate was made for this behavior on the basis of small-crack data [5] and it is shown by the solid line below rates of about $2 \mathrm{E}-09 \mathrm{~m} / \mathrm{cycle}$. The baseline relation shown by the solid line (see Table 1) will be used later to predict fatigue lives under constant-amplitude and spectrum loading.

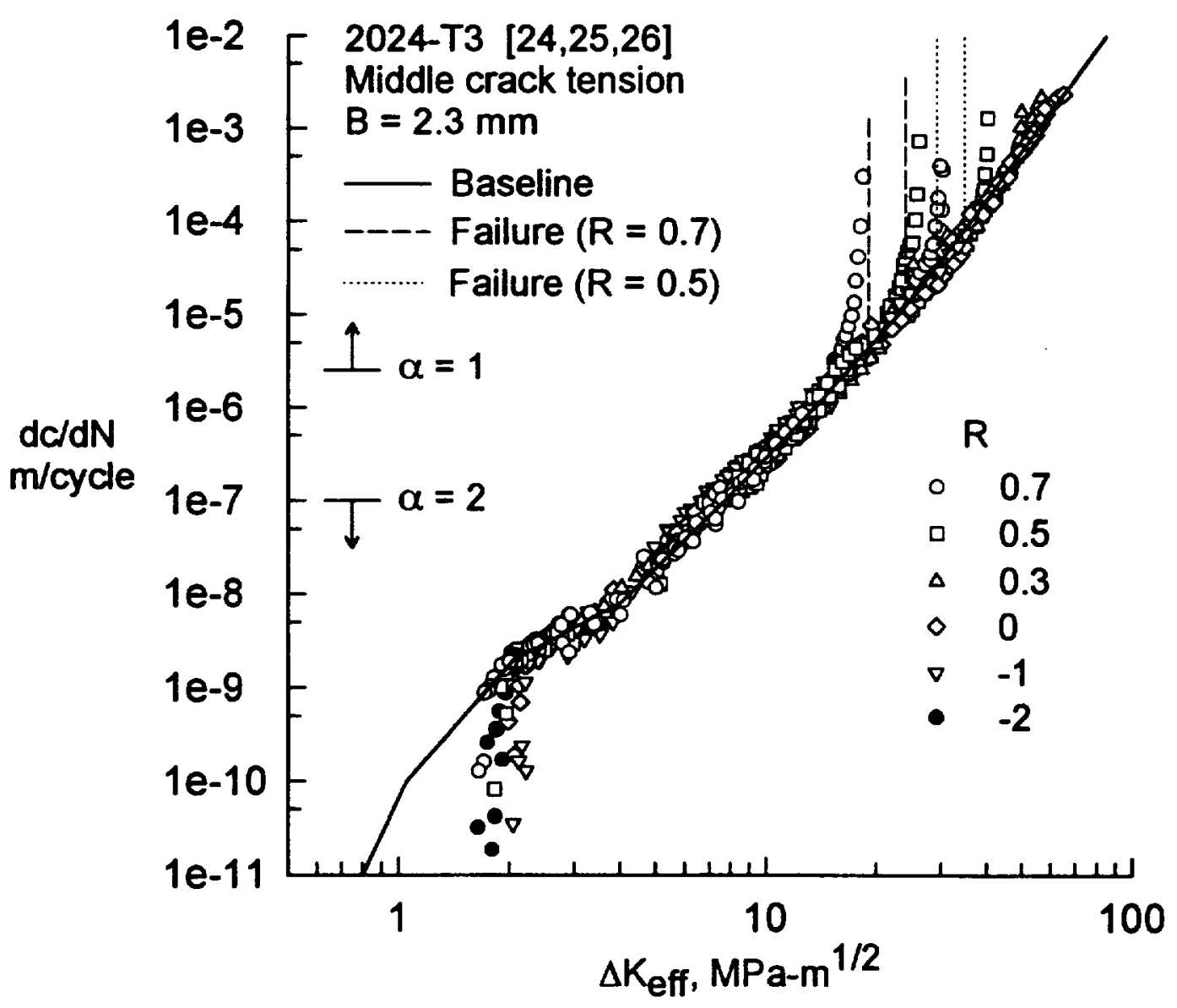

Figure 3. Effective stress-intensity factor range against crack-growth rate for large cracks in 2024-T3 aluminum alloy sheet. 
Table 1. - Mechanical, fracture and baseline crack-growth ( $\Delta \mathrm{K}_{\mathrm{eff}}$-rate) properties.

\begin{tabular}{|c|c|c|c|c|c|}
\hline \multicolumn{2}{|c|}{$\begin{array}{l}2024-\mathrm{T} 3 \\
\mathrm{~B}=2.3 \mathrm{~mm}\end{array}$} & \multicolumn{2}{|c|}{$\begin{array}{l}7075-\mathrm{T} 6 \\
\mathrm{~B}=2.3 \mathrm{~mm}\end{array}$} & \multicolumn{2}{|c|}{4340 Steel } \\
\hline \multicolumn{2}{|c|}{$\begin{array}{l}\sigma_{y s}=360 \mathrm{MPa} \\
\sigma_{u}=490 \mathrm{MPa} \\
E=72000 \mathrm{MPa}\end{array}$} & \multicolumn{2}{|c|}{$\begin{array}{l}\sigma_{\mathrm{u}}=575 \mathrm{MPa} \\
\mathrm{E}=72000 \mathrm{MPa}\end{array}$} & \multicolumn{2}{|c|}{$\begin{array}{l}\sigma_{\mathrm{u}}=1510 \mathrm{MPa} \\
\mathrm{E}=207000 \mathrm{MPa}\end{array}$} \\
\hline \multicolumn{2}{|c|}{$\begin{array}{l}\mathrm{K}_{\mathrm{F}}=267 \mathrm{MPa} / \mathrm{m} \\
\mathrm{m}=1.0\end{array}$} & \multicolumn{2}{|c|}{$\begin{array}{l}\mathrm{K}_{\mathrm{F}}=50 \mathrm{MPa} \sqrt{\mathrm{m}} \\
\mathrm{m}=0.0\end{array}$} & \multicolumn{2}{|c|}{$\begin{aligned} \mathrm{K}_{\mathrm{F}} & =170 \mathrm{MPa} / \mathrm{m} \\
\mathrm{m} & =0.0\end{aligned}$} \\
\hline$\Delta \mathrm{K}_{\mathrm{eff}}$ & $\mathrm{dc} / \mathrm{dN}$ & $\Delta \mathrm{K}_{\mathrm{eff}}$ & $\mathrm{dc} / \mathrm{dN}$ & $\Delta \mathrm{K}_{\mathrm{eff}}$ & $\mathrm{dc} / \mathrm{dN}$ \\
\hline $\mathrm{MPa} \sqrt{\mathrm{m}}$ & m/cycle & $\mathrm{MPa} \sqrt{\mathrm{m}}$ & $\mathrm{m} /$ cycle & $\mathrm{MPa} / \mathrm{m}$ & m/cycle \\
\hline 0.8 & $1.0 \mathrm{E}-11$ & 0.9 & $1.0 \mathrm{E}-11$ & 3.2 & $1.0 \mathrm{E}-11$ \\
\hline 1.05 & $1.0 \mathrm{E}-10$ & 1.25 & $1.0 \mathrm{E}-09$ & 3.75 & $5.0 \mathrm{E}-10$ \\
\hline 2.05 & $2.0 \mathrm{E}-09$ & 3.0 & $1.0 \mathrm{E}-08$ & 5.2 & $2.0 \mathrm{E}-09$ \\
\hline 4.0 & $8.0 \mathrm{E}-09$ & 4.0 & $6.3 \mathrm{E}-08$ & 7.3 & $7.0 \mathrm{E}-09$ \\
\hline 7.7 & $1.0 \mathrm{E}-07$ & 10.0 & $1.0 \mathrm{E}-06$ & 14.0 & $5.0 \mathrm{E}-08$ \\
\hline 13.5 & $1.0 \mathrm{E}-06$ & 14.8 & $1.0 \mathrm{E}-05$ & 50.0 & $6.5 \mathrm{E}-07$ \\
\hline 23.0 & $1.0 \mathrm{E}-05$ & 23.0 & $1.0 \mathrm{E}-04$ & 108.0 & $1.0 \mathrm{E}-04$ \\
\hline 36.0 & $1.0 \mathrm{E}-04$ & & & & \\
\hline 85.0 & $1.0 \mathrm{E}-02$ & & & & \\
\hline$\alpha$ & $\begin{array}{l}\mathrm{dc} / \mathrm{dN} \\
\mathrm{m} / \mathrm{cycle}\end{array}$ & $\alpha$ & $\begin{array}{l}\mathrm{dc} / \mathrm{dN} \\
\mathrm{m} / \mathrm{cycle}\end{array}$ & $\alpha$ & $\begin{array}{l}\mathrm{dc} / \mathrm{dN} \\
\mathrm{m} / \mathrm{cycle}\end{array}$ \\
\hline 2.0 & $1.0 \mathrm{E}-07$ & 1.8 & $7.0 \mathrm{E}-07$ & 2.5 & $5.0 \mathrm{E}-07$ \\
\hline 1.0 & $2.5 \mathrm{E}-06$ & 1.2 & $7.0 \mathrm{E}-06$ & 1.2 & $2.5 \mathrm{E}-05$ \\
\hline
\end{tabular}

Aluminum Alloy 7075-T6

The large-crack results for 7075-T6 aluminum alloy are shown in Figure 4 for data generated at two different laboratories and at three stress ratios (Phillips and Deng, see Ref. 27 or 28). The data collapsed into a narrow band, again, with several transitions in slope occurring at about the same rate for all stress ratios. These data demonstrate why a table-lookup $\Delta \mathrm{K}_{\text {eff }}$ - rate curve is needed to fit crack-growth rate data over many orders of magnitude in rate. Some differences 


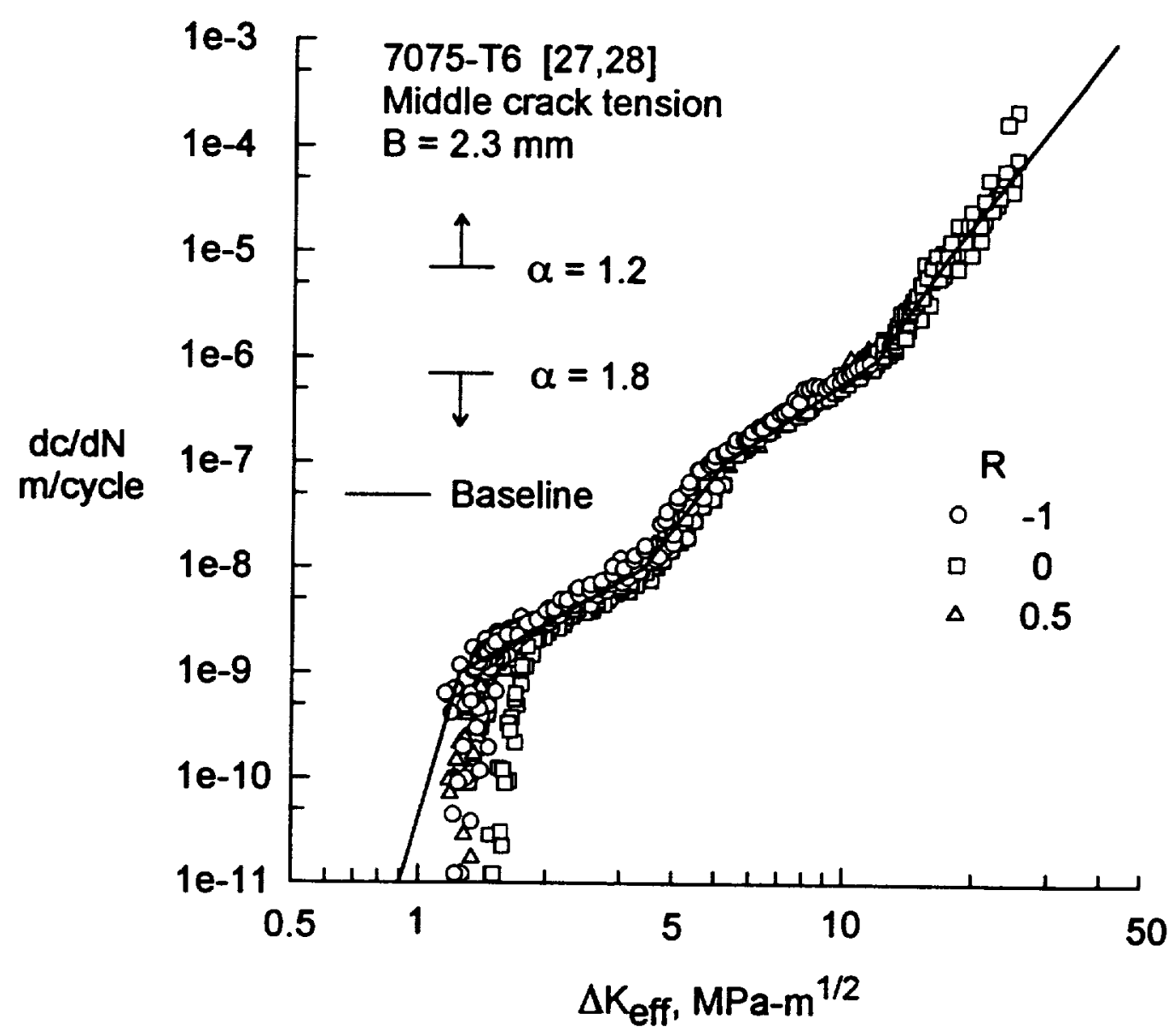

Figure 4. Effective stress-intensity factor range against crack-growth rate for large cracks in 7075-T6 aluminum alloy sheet.

were observed in the near threshold regime. For these calculations, a constraint factor $\alpha$ of 1.8 was used for rates less than $7 \mathrm{E}-07 \mathrm{~m} /$ cycle and $\alpha$ equal to 1.2 for rates greater than $7 \mathrm{E}-06$ $\mathrm{m} / \mathrm{cycle}$. Again, the values of $\alpha$ and rate were selected by trial-and-error. For this sheet alloy, the constraint-loss regime occurs near $\left(\Delta \mathrm{K}_{\mathrm{eff}}\right)_{\mathrm{T}}=13.1 \mathrm{MPa} / \mathrm{m}$. In the threshold regime, an estimate was made to fit small-crack growth rate behavior (see Ref. 28) and it is shown by the solid line below a rate of about $2 \mathrm{E}-09 \mathrm{~m} / \mathrm{cycle}$. The baseline relation shown by the solid line (see Table 1) will be used later to predict small-crack growth rates and fatigue lives under constant-amplitude and spectrum loading.

\section{Steel 4340}

The large-crack results for the 4340 steel are shown in Figure 5 for data generated at two different laboratories and at four stress ratios (see Swain et al. [29]). For these calculations, a 
constraint factor $\alpha$ of 2.5 was used for rates less than $5 \mathrm{E}-07 \mathrm{~m} /$ cycle and $\alpha$ equal to 1.2 for rates greater than 2.5E-05 m/cycle. Again, the values of $\alpha$ and rate were selected by trial-and-error. For this material and thickness, the constraint-loss regime occurs near $\left(\Delta \mathrm{K}_{\mathrm{eff}}\right)_{\mathrm{T}}=52 \mathrm{MPa} / \mathrm{m}$, which corresponds closely to the sharp change in growth rates at about $1 \mathrm{E}-06 \mathrm{~m} /$ cycle. The data collapsed into a fairly tight band, in the mid-rate regime, but some differences were observed in the near threshold regime. For the high-strength steel, small- and large-crack data tended to agree in the near threshold regime (see Ref. 29). The baseline relation shown by the solid line (see Table 1) will be used later to predict fatigue lives under constant-amplitude and spectrum loading.

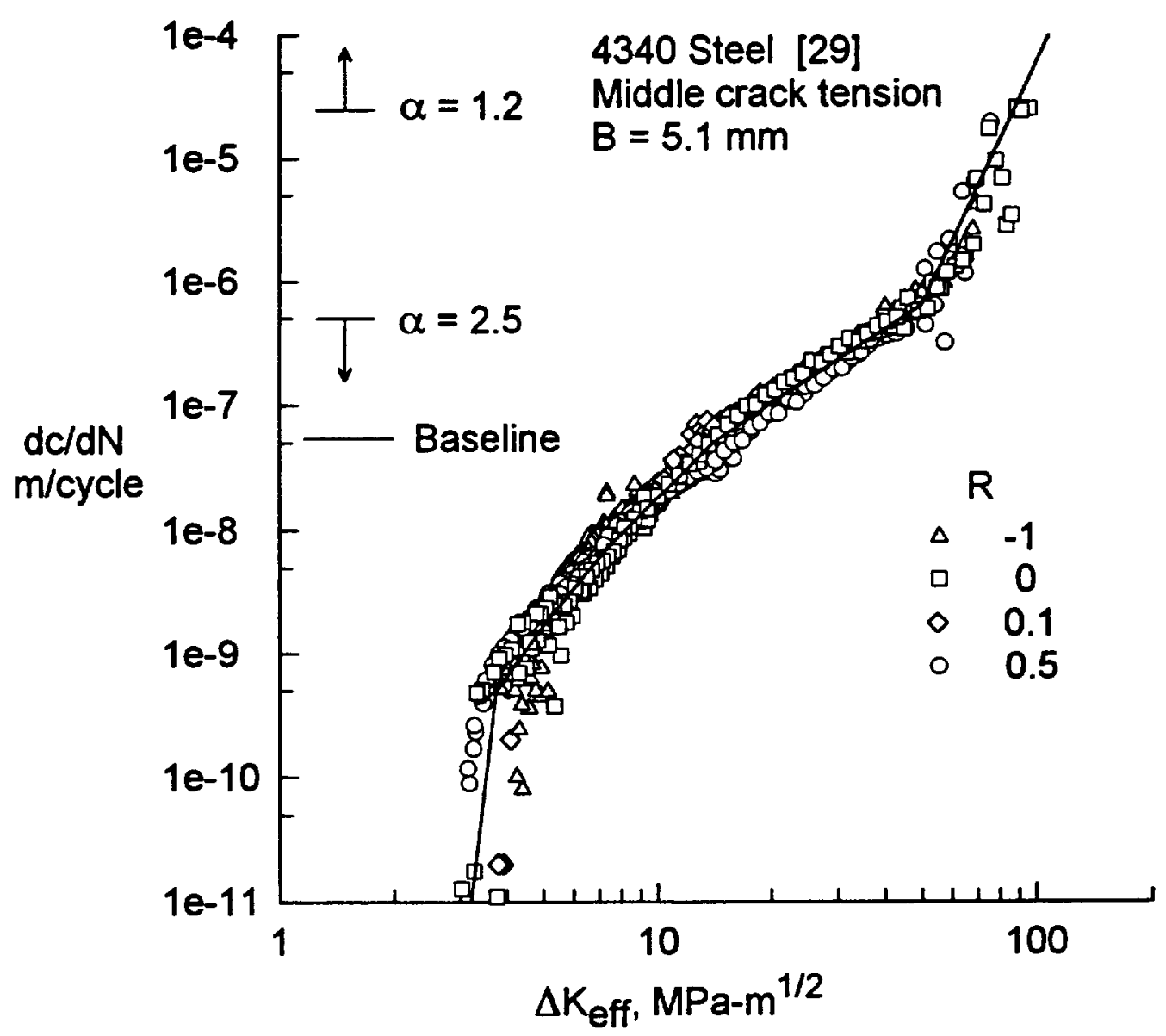

Figure 5. Effective stress-intensity factor range against crack-growth rate for large cracks in 4340 steel. 


\section{SMALI-CRACK GROWTH RATE BEHAVIOR}

Earlier work by Pearson [1] on fatigue-crack initiation and growth of small cracks from inclusions particles in two aluminum alloys (BS L65 and DTD 5050) set the stage for the development of the small-crack theory. His results are shown in Figure 6, as the dashed curve, along with additional small- and large-crack data from Lankford [37] on 7075-T6 aluminum alloy. Pearson concluded that cracks of about the size of the average grain-size, grew several times faster than large cracks at nominally identical $\Delta \mathrm{K}$ values. The open symbols and dash-dot curve show the large-crack data and the development of the large-crack threshold at about 3 to $4 \mathrm{MPa} \sqrt{\mathrm{m}}$. The light solid lines show measured small-crack growth rates, from small surface cracks, with growth at $\Delta \mathrm{K}$ levels as low as $1.5 \mathrm{MPa} / \mathrm{m}$. Some general observations, by Lankford [37], were that the minimum in $\mathrm{da} / \mathrm{dN}$ occurred when the crack depth, a, was about the minimum dimension of the pancake grain (subsurface grain boundary) and that the magnitude of the lower rates was controlled by the degree of micro-plasticity in the next grain penetrated by the crack. If the next grain is oriented like the first, then no deceleration will occur, as indicated by the uppermost smallcrack curves in Figure 6.

At this stage, it would be of interest to compare the test results from Pearson and Lankford with the small-crack growth predictions made from the crack-closure model and the large-crack data shown in Figure 4. The $\Delta \mathrm{K}_{\text {eff }}$ - rate relation for the 7075-T6 alloy [27,28] is shown as the dotted lines (see Fig. 4). The lower section of the $\Delta \mathrm{K}_{\text {eff }}$ - rate relation (below $2 \mathrm{E}-06 \mathrm{~mm} / \mathrm{cycle}$ ) was estimated on the basis of small-crack data, also generated in Reference 28 . The $\Delta \mathrm{K}_{\text {eff }}$ - rate relation is closure free and this is the starting point for all small cracks because these cracks are assumed to be fully open on the first cycle. The results of an analysis of the test specimen used by Lankford is shown by the heavy solid curve. The initial defect was selected as a $10 \mu \mathrm{m}$ radius semi-circular surface crack, so that the 2 a dimension (on the surface) would be $20 \mu \mathrm{m}$. As the small crack grew, the closure level increased much faster than the $\Delta K$ level and a rapid decrease in rates was calculated. This rapid drop is a combination of the closure transient and the sharp change in slope of the $\Delta \mathrm{K}_{\text {eff }}$ - rate curve at about $1 \mathrm{E}-06 \mathrm{~mm} / \mathrm{cycle}$. At about $30 \mu \mathrm{m}$, the crackopening stresses from the model had nearly stabilized (apparent by the fact that the heavy solid line is parallel to the dotted line). Also, the effects of plasticity on the crack-driving force, like equation (2), is quite small considering that the applied stress level was 0.75 times the flow stress (see Fig. 6 in Ref. 10). The predicted results for the small-crack growth rates are in excellent agreement with Pearson's data and agree with Lankford's data which do not exhibit a grain- 


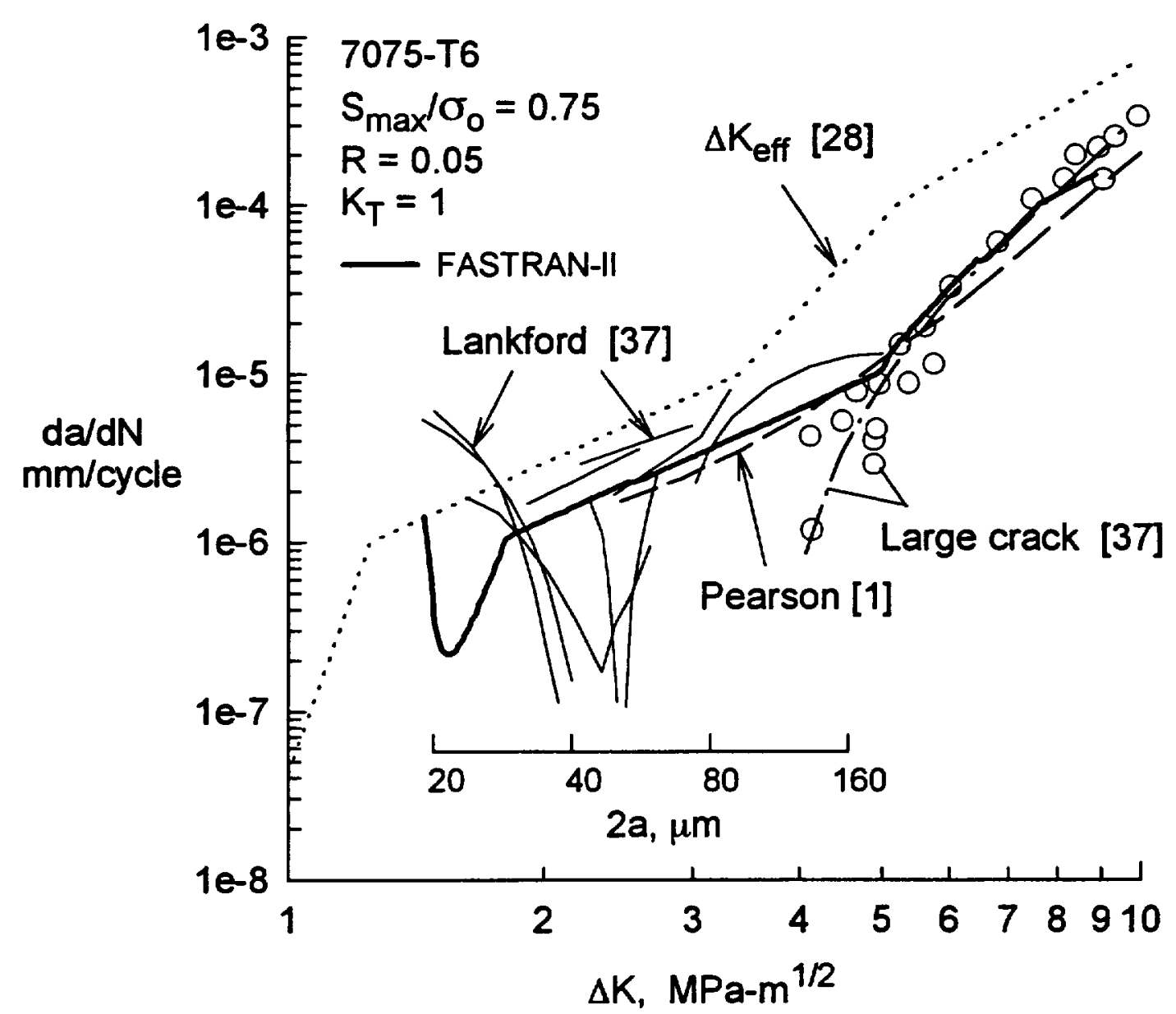

Figure 6. Measured and predicted small- and large-surface crack-growth rates in an aluminum alloy.

boundary influence. Interestingly, the small-crack analysis shows a single dip in the small-crack curve, similar to the "single" dip observed in some of Lankford's small-crack data. Would the grain-boundary interaction always occur at the same crack length $(40 \mu \mathrm{m})$ ? Why aren't there other dips, or small indications of a dip, in the rate curve at 80,120 or $160 \mu \mathrm{m}$ ? Further study is needed to help resolve these issues. The following section will review the use of "small-crack theory" to predict or calculate fatigue life for un-notched and notched specimens under various load histories. 


\section{FATIGUE-LIFE PREDICTIONS}

At this point, all of the elements are in place to assess "small-crack theory" -- a total fatiguelife prediction methodology based solely on crack propagation from microstructural features. In this approach, a crack is assumed to initiate and grow from a microstructural feature on the first cycle. The crack-closure model and the baseline $\Delta \mathrm{K}_{\mathrm{eff}}$-rate curve are used to predict crack growth from the initial crack size to failure. The final crack size was calculated from the fracture toughness of the material, except where noted. Comparisons are made with fatigue tests conducted on un-notched tension, circular-hole tension and single- or double-edge-notch tension specimens. Results are presented for two aluminum alloys and a high-strength steel under either constant-amplitude or spectrum loading.

Aluminum Alloy 2024-T3

Grover et.al [38] conducted fatigue tests on flat $\left(K_{T}=1\right)$ dog-bone specimens (Fig. 2a) made of 2024-T3 aluminum alloy under $R=0$ and -1 loading. The specimens were electro-polished but no information on crack-initiation sites was available. Thus, in the analyses it was assumed that cracks initiated as quarter-circular corner cracks. A comparison of experimental and calculated fatigue lives is shown in Figure 7. Various initial crack sizes were selected by trial-and-error to find the best value to fit the test data. Analyses with a 20- $\mu \mathrm{m}$ initial crack size fit the test data quite well for both $R$ ratios. Results for each $R$ ratio approached the flow stress $\sigma_{0}$ (average of the yield stress and ultimate tensile strength) for high applied stress levels. Some discrepancies were observed for both $\mathbf{R}=0$ and -1 analyses at applied stress levels above the yield stress. These discrepancies were expected because the closure model does not account for strainhardening effects but uses an average flow stress. To fit fatigue limits, a value of $\left(\Delta \mathrm{K}_{\mathrm{eff}}\right)_{\text {th }}$ of 0.8 $\mathrm{MPa} \sqrt{\mathrm{m}}$ was needed for the $20-\mu \mathrm{m}$ initial crack. 


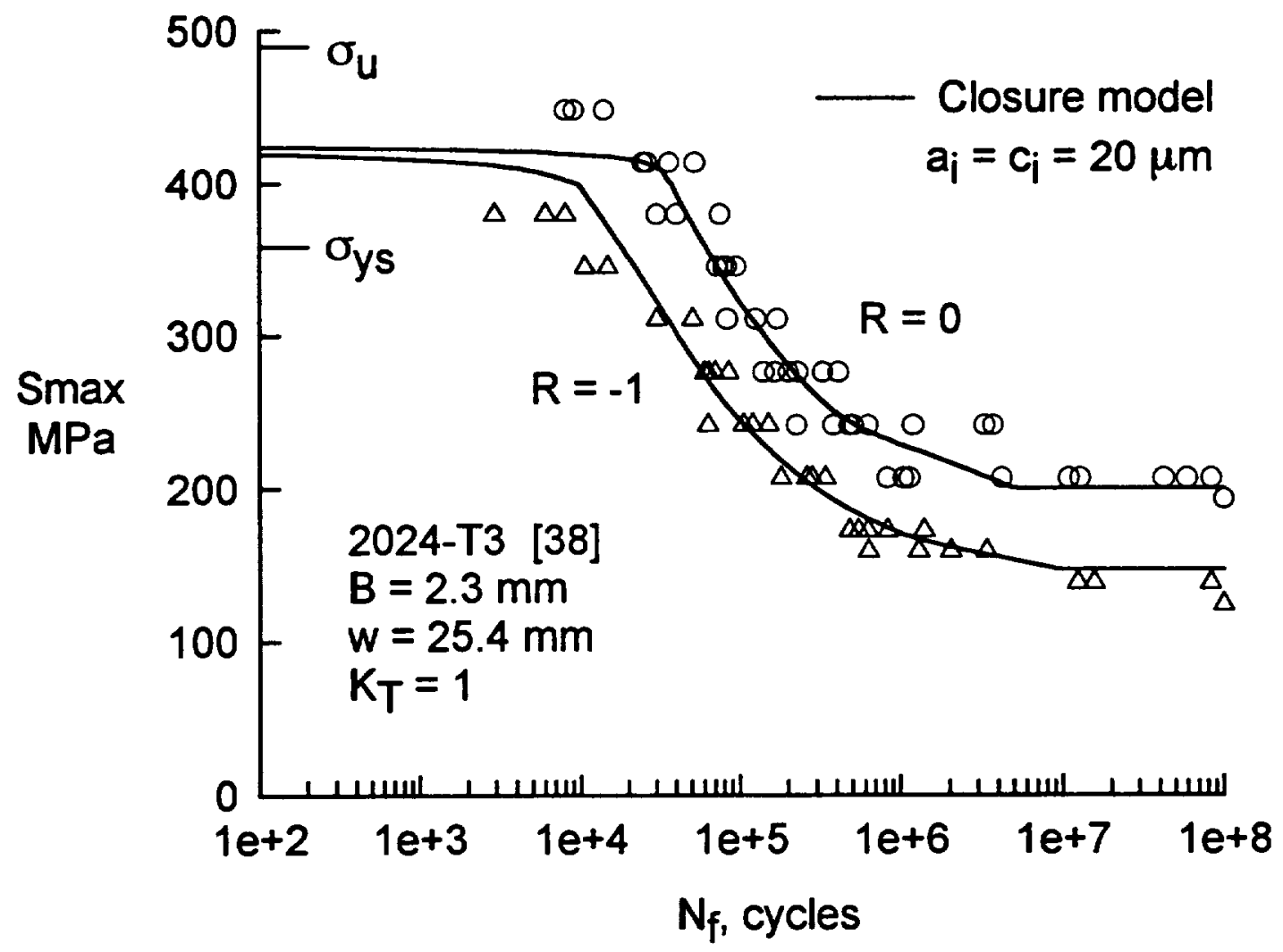

Figure 7. Measured and calculated fatigue lives for 2024-T3 aluminum alloy un-notched specimens. 
Landers and Hardrath [39] determined the fatigue lives of 2024-T3 aluminum alloy specimens with a central hole (Fig. 2b). The results for specimens with a hole radius of $1.6 \mathrm{~mm}$ are shown in Figure 8. Predicted results, as shown by the curves, were made using an initial semi-circular crack size $(6 \mu \mathrm{m})$ that had an equal area to the average inclusion-particle sizes that initiated cracks [5]. Results from the elastic-plastic analyses (eqn. 2) agreed fairly well with the test data, but the elastic analyses (eqn. 1) over-predicted fatigue lives at the high stress levels. The elastic-plastic analyses tended to underpredict lives for $R=0$ and slightly over-predict lives for $R=-1$. The influence of stress ratio on fatigue limits was predicted quite well using a value of $\left(\Delta \mathrm{K}_{\text {eff }}\right.$ )th of $0.8 \mathrm{MPa} V_{\mathrm{m}}$ (determined from the un-notched specimens, Fig. 8). The smaller initial crack size for a notched specimen compared to that for the un-notched specimen $(20 \mu \mathrm{m})$ is probably due to a much smaller volume of material under the stress that caused failure.

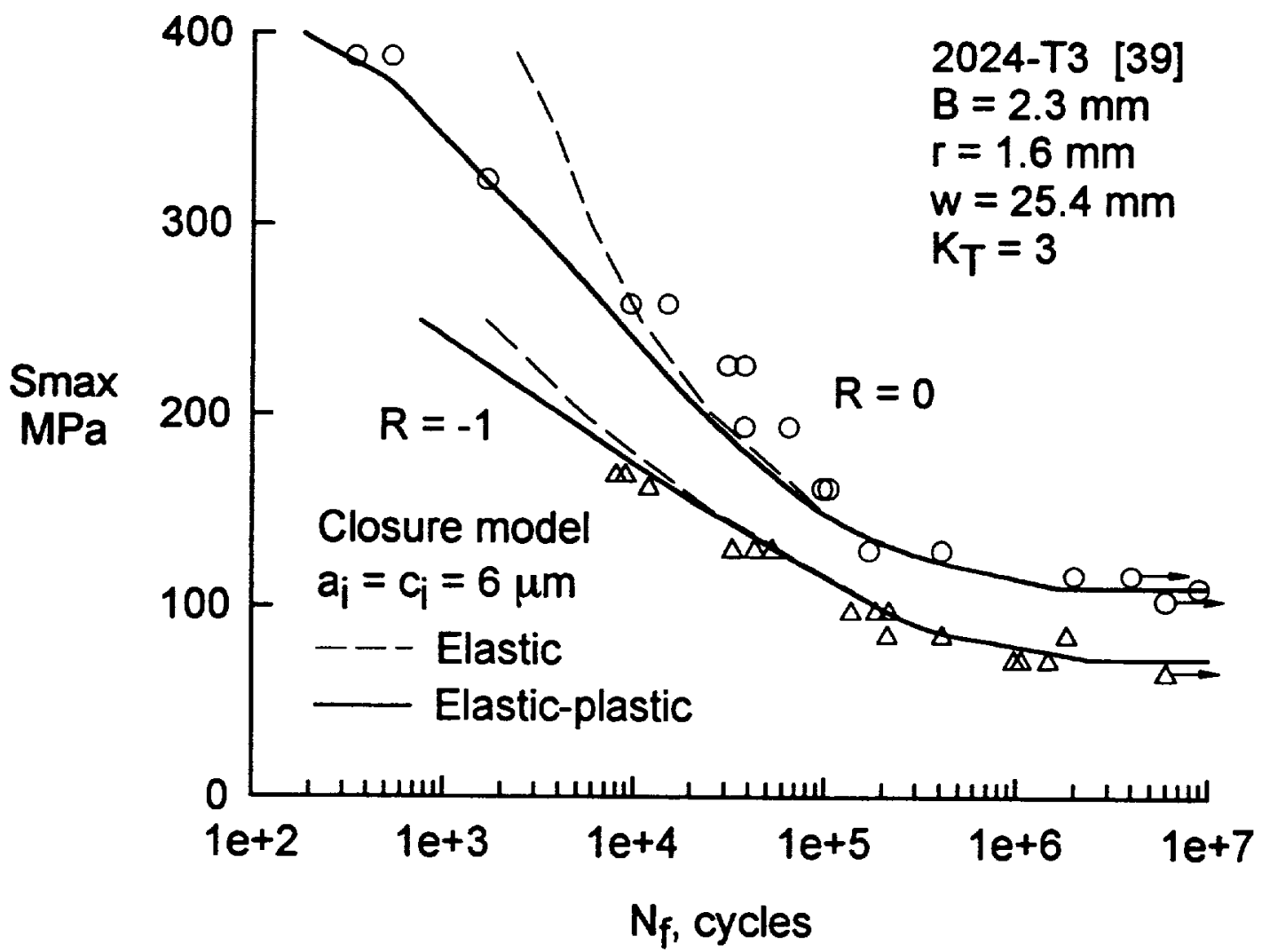

Figure 8. Measured and calculated fatigue lives for 2024-T3 aluminum alloy circular-hole specimens. 
Comparisons of experimental and predicted fatigue lives for 2024-T3 single-edge-notch tension (SENT) specimens (Fig. 2c) under the FALSTAFF [19], Gaussian [20], and TWIST [21] load sequences are shown in Figure 9. The specimens were cycled until a crack had grown across the full thickness, that is $2 a_{\mathrm{f}}=\mathrm{B}$. The predictions were made using the same initial crack size used for the previous constant-amplitude predictions $(6 \mu \mathrm{m})$. The predicted lives, again, agreed well with the test data. For these conditions, the elastic and elastic-plastic analyses showed very little difference.

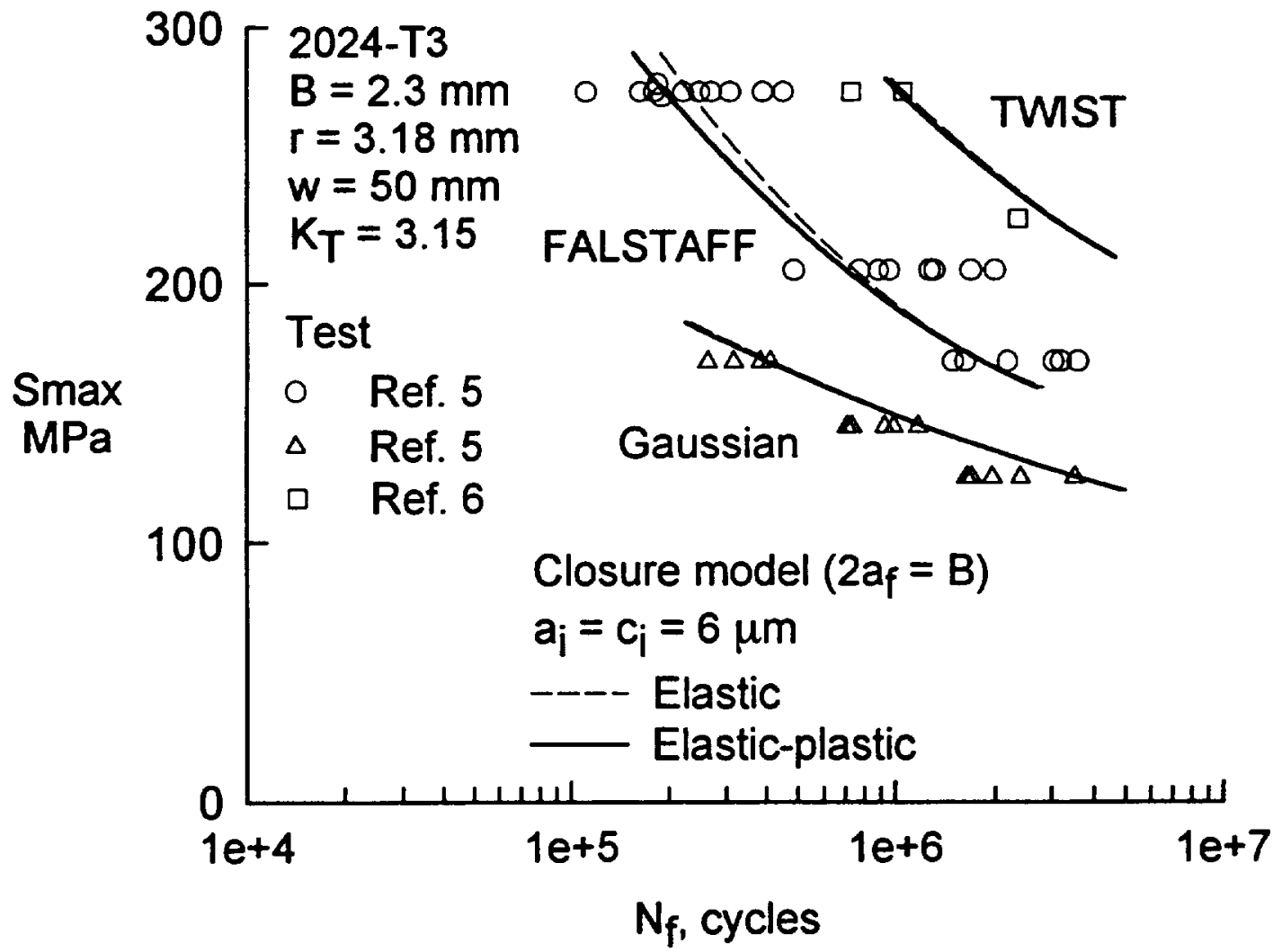

Figure 9. Measured and predicted fatigue lives for 2024-T3 aluminum alloy SENT specimens under various spectrum loading. 
Aluminum Alloy 7075-T6

Again, Grover et.al [38] conducted fatigue tests on flat dog-bone specimens made of 7075T6 aluminum alloy. The specimens were also electro-polished. In the analyses it was assumed that cracks initiated as quarter-circular comer crack at a specimen edge. A comparison of experimental and calculated fatigue lives is shown in Figure 10. Similar to the 2024-T3 alloy, a $20-\mu \mathrm{m}$ initial crack size fit the mean of the test data at $R=0$ quite well. The $20-\mu \mathrm{m}$ initial crack size was also able to predict the behavior of 7075-T6 fatigue specimens tested at $R=-1$ (not shown).

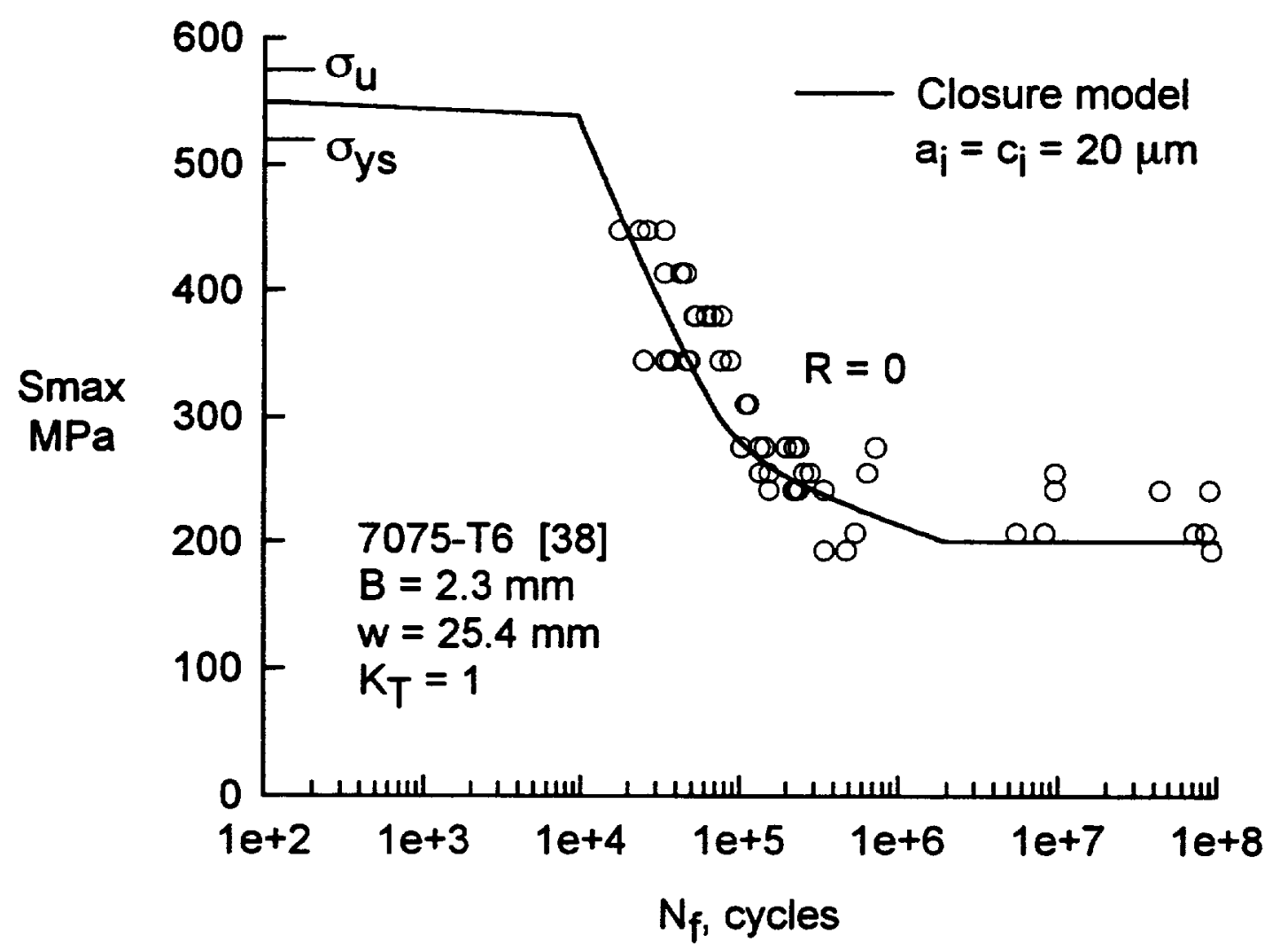

Figure 10. Measured and calculated fatigue lives for 7075-T6 aluminum alloy un-notched specimens. 
The results of fatigue tests conducted on 7075-T6 specimens [39] with a hole radius of 0.8 $\mathrm{mm}$ are shown in Figure 11 (symbols). Predicted results were, again, made using an initial semicircular crack size $(6 \mu \mathrm{m})$ that had an area equal to the average inclusion-particle sizes that had initiated cracks $[27,28]$. Results from the elastic-plastic analyses (eqn. 2) agreed fairly well with the test data. Again, the analyses tended to underpredict for $R=0$ and slightly over-predict for $R$ $=-1$, similar to the trends observed for the 2024-T3 specimens (Fig. 8). The reason for these discrepancies is unknown but it may be related to assuming a mathematical surface crack on the first cycle instead of a crack initiating from an inclusion-particle cluster or void (see Bowles and Schijve [40]). The fatigue limits were predicted quite well using a value of $\left(\Delta \mathrm{K}_{\mathrm{eff}}\right)$ th 0.75 $\mathrm{MPa} \sqrt{\mathrm{m}}$ with the 6- $\mu \mathrm{m}$ initial crack.

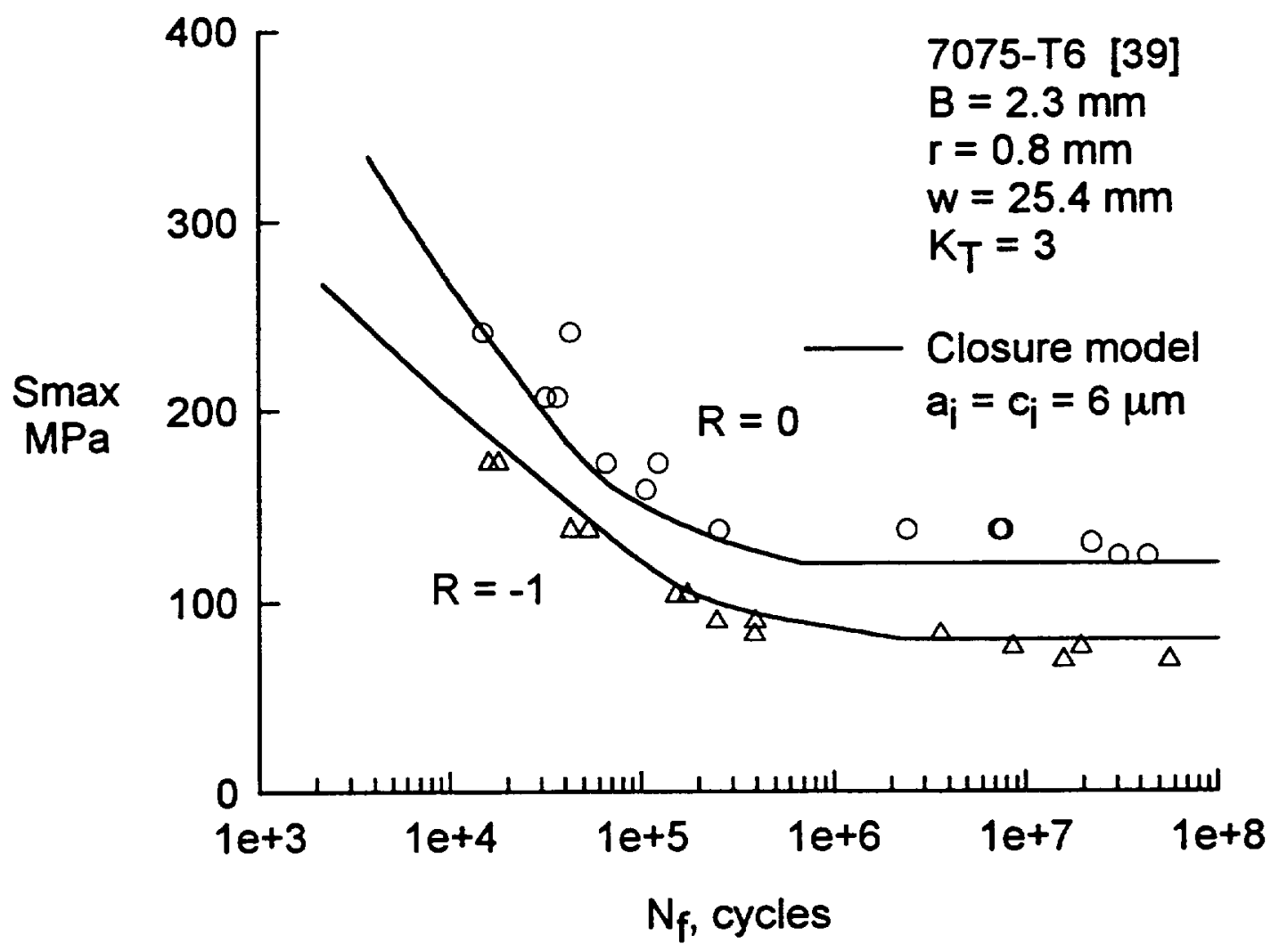

Figure 11. Measured and calculated fatigue lives for 7075-T6 aluminum alloy circular-hole specimens. 
Experimental and predicted results for fatigue tests conducted on 7075-T6 specimens under the Mini-TWIST wing spectrum are shown in Figure 12. These tests were conducted on SENT specimens $[27,28]$ that were cycled to failure. The predictions were made using an initial semicircular defect size that was close to the average inclusion-particle sizes where cracks initiated. The predicted lives were in good agreement with the test results.

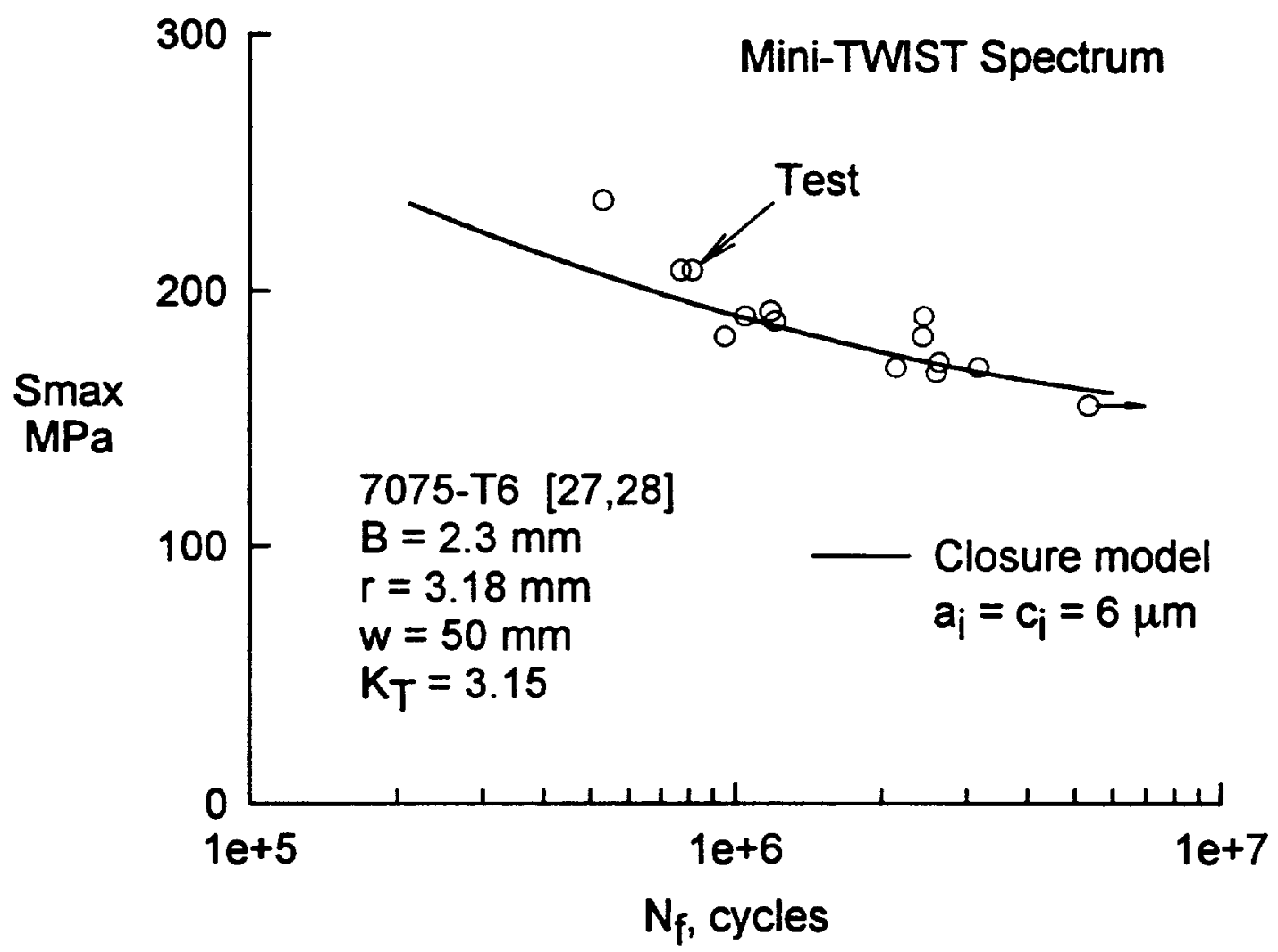

Figure 12. Measured and predicted fatigue lives for 7075-T6 aluminum alloy SENT specimens under Mini-TWIST spectrum loading. 
Steel 4340

Swain et.al. [29] conducted fatigue and small-crack tests on 4340 steel single-edge-notch tension specimens. These tests were conducted under both constant-amplitude and spectrum loading. Inspection of fatigue surfaces showed that in each case a crack had initiated at an inclusion particle defect. The initiation site was either at a spherical (calcium-aluminate) or a stringer (manganese sulfide) inclusion particle. Examination of initiation sites for over 30 fatigue cracks produced information on the distribution of crack initiation site dimensions. The spherical particle defects range in size from 10 to $40 \mu \mathrm{m}$ in diameter. The stringer particles were typically 5 to 20 $\mu \mathrm{m}$ in the thickness direction and range up to $60 \mu \mathrm{m}$ in the width direction. The median values of the defect dimensions measured were $a_{i}=8 \mu \mathrm{m}$ and $c_{i}=13 \mu \mathrm{m}$. An equivalent area (semicircular) defect is $10 \mu \mathrm{m}$. This initial defect size will be used later to predict fatigue lives.

Figure 13 shows test data (symbols) obtained from notched specimens tested at three stress ratios. Using a 10- $\mu \mathrm{m}$ initial semi-circular surface crack located at the center of the notch and the baseline crack-growth relation (Fig. 5), predicted fatigue lives are shown by the solid curves. A small-crack effective threshold, $\left(\Delta \mathrm{K}_{\text {eff }}\right.$ ) th, of $3.2 \mathrm{MPa} \sqrt{\mathrm{m}}$ was used to predict the endurance limits quite accurately. For the 4340 steel, the large-crack and small-crack thresholds were the same. 


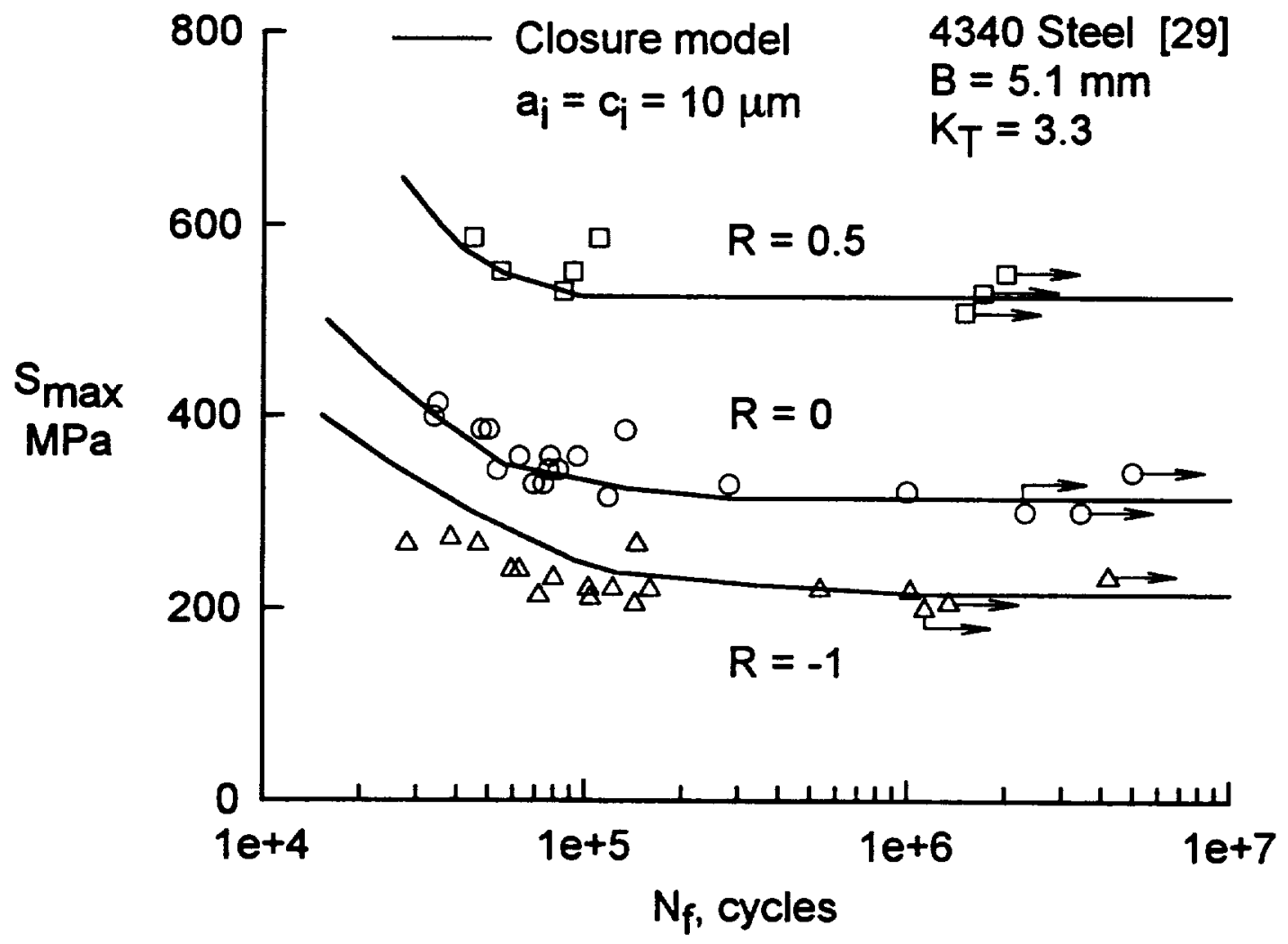

Figure 13. Measured and predicted fatigue lives for $\mathbf{4 3 4 0}$ steel SENT specimens. 
The results of fatigue life tests under the Felix/28 load sequence are shown in Figure 14 as symbols. The type of defect that initiated the fatigue failures are identified. Predictions of total fatigue life under the Felix/28 load spectrum were made using the closure model by calculating the number of cycles necessary to grow a crack from the assumed initial defect size $(10 \mu \mathrm{m})$, located at the center of the notch root, to failure. The predicted results agreed well with the test data.

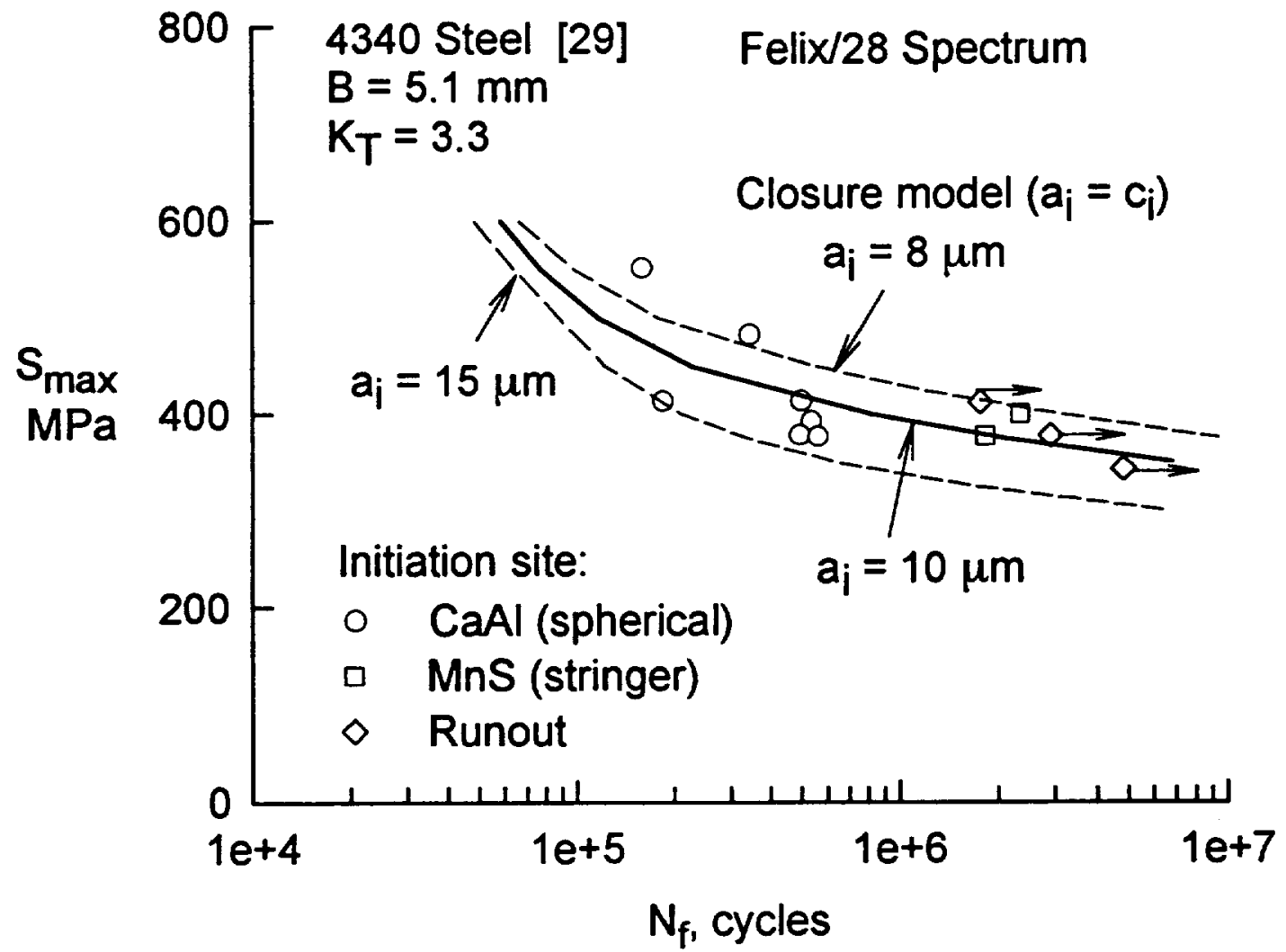

Figure 14. Measured and predicted fatigue lives for 4340 steel SENT specimens under Felix/28 spectrum loading.

\section{CONCLUDING REMARKS}

A "plasticity-induced" crack-closure model was used to correlate large-crack growth rate data on two aluminum alloys and a steel under constant-amplitude loading for a wide range of stress ratios. A constraint factor, which accounts for three-dimensional state-of-stress effects, was used in determining the effective stress-intensity factor range against rate relations.

Comparisons made between measured and predicted small-crack growth rates for an aluminum 
alloy showed that the closure model could predict the trends that were observed in the tests. Using the closure model and some microstructural features, such as inclusion-particle sizes, a total fatigue-life prediction method was demonstrated. Calculated and predicted fatigue lives for un-notched and notched specimens made of two aluminum alloys compared well with test data under constant-amplitude and spectrum loading. Similarly, predicted fatigue lives for notched specimens made of a high-strength 4340 steel also compared well with test data under constantamplitude and spectrum loading.

\section{ACKNOWLEDGEMENTS}

The authors take this opportunity to thank our colleagues, Drs. Peter Edwards and X. R. Wu, for their leadership in the AGARD Structures and Materials Panel Short-Crack Programme and the NASA/CAE Cooperative Program on Fatigue and Fracture Mechanics, respectively. Their guidance, and the efforts of the many participants in both programs, have contributed to making Small-Crack Theory successful.

\section{REFERENCES}

[1] Pearson, S., "Initiation of Fatigue Cracks in Commercial Aluminum Alloys and the Subsequent Propagation of Very Short Cracks, " Engineering Fracture Mechanics, Vol. 7, No. 2, 1975, pp. 235-247.

[2] Ritchie, R. O. and Lankford, J., eds., Small Fatigue Cracks, The Metallurgical Society, Inc., Warrendale, PA., 1986.

[3] Miller, K. J. and de los Rios, E. R., eds., The Behaviour of Short Fatigue Cracks, European Group on Fracture, Publication No. 1, 1986.

[4] Zocher, H., ed., Behaviour of Short Cracks in Airframe Components, AGARD CP-328, 1983.

[5] Newman, J. C., Jr. and Edwards, P. R., "Short-Crack Growth Behaviour in an Aluminum Alloy - an AGARD Cooperative Test Programme," AGARD R-732, 1988.

[6] Edwards, P. R. and Newman, J. C., Jr., eds., Short-Crack Growth Behaviour in Various Aircraft Materials, AGARD Report No. 767, 1990.

[7] Raju, I. S. and Newman, J. C., Jr., "Stress-Intensity Factors for a Wide Range of SemiElliptical Surface Cracks in Finite-Thickness Plates," Engineering Fracture Mechanics, Vol. 11, No. 4, 1979, pp. 817-829.

[8] Newman, J. C., Jr. and Raju, I. S., "Stress-Intensity Factor Equations for Cracks in ThreeDimensional Finite Bodies," ASTM STP 791, Vol. I, 1983, pp. 238-265. 
[9] El Haddad, M. H.; Dowling, N. E.; Topper, T. H. and Smith, K. N., "J Integral Application for Short Fatigue Cracks at Notches," International Journal of Fracture, Vol. 16, 1980, pp. 15-30.

[10] Newman, J. C., Jr., "Fracture Mechanics Parameters for Small Fatigue Cracks," Small Crack Test Methods, ASTM STP 1149, J. Allison and J. Larsen, eds., 1992, pp. 6-28.

[11] Leis, B. N.; Kanninen, M. F.; Hopper, A. T.; Ahmad, J. and Broek, D., "Critical Review of the Fatigue Growth of Short Cracks," Engineering Fracture Mechanics, Vol. 23, 1986, pp. 883-898.

[12] Elber, W., "The Significance of Fatigue Crack Closure," Damage Tolerance in Aircraft Structures, ASTM STP 486, 1971, pp. 230-242.

[13] Nisitani, H. and Takao, K. I., "Significance of Initiation, Propagation and Closure of Microcracks in High Cycle Fatigue of Ductile Materials," Engineering Fracture Mechanics, Vol. 15, No. 3, 1981, pp. 455-456.

[14] Minakawa, K. and McEvily, A. J., "On Near-Threshold Fatigue Crack Growth in Steels and Aluminum Alloys," Proceedings of the International Conference on Fatigue Thresholds, Vol. 2, 1981, pp. 373-390.

[15] Newman, J. C., Jr., "A Nonlinear Fracture Mechanics Approach to the Growth of Small Cracks," Behaviour of Short Cracks in Airframe Components, H. Zocher, ed., AGARD CP-328, 1983, pp. 6.1-6.26.

[16] Newman, J. C., Jr., "A Crack-Closure Model for Predicting Fatigue Crack Growth under Aircraft Spectrum Loading," Methods and Models for Predicting Fatigue Crack Growth under Random Loading, J. B. Chang and C. M. Hudson, eds., ASTM STP 748, 1981, pp. 53-84.

[17] Newman, J. C., Jr., "A Crack-Opening Stress Equation for Fatigue Crack Growth," International Journal of Fracture, Vol. 24, 1984, R131-R135.

[18] Rudd, J. L., Yang, J. N., Manning, S. D. and Garver, W. R., "Durability Design Requirements and Analysis for Metallic Airframes," Design of Fatigue and Fracture Resistant Structures, ASTM STP 761, P. R. Abelkis and C. M. Hudson, eds., 1982, pp. 133-151.

[19] van Dijk, G. M. and deJonge, J. B., "Introduction to a Fighter Loading Standard for Fatigue Evaluation--FALSTAFF," NLR MP 75017 U, Nationaal Lucht-en Ruimtevaartlaborium, 1975.

[20] Huck, M.; Schutz, W.; Fischer, R. and Kobler, H. G., "A Standard Random Load Sequence of Gaussian Type Recommended for General Application in Fatigue Testing," IABG Report No. TF-570 or LBF Report No. 2909, Germany, 1976. 
[21] deJonge, J. B.; Schutz, D.; Lowak, H. and Schijve, J., "A Standardized Load Sequence for Flight Simulation Tests on Transport Aircraft Wing Structures (TWIST)," NLR TR-73029 U, Nationaal Lucht-en Ruimtevaartlaborium, Netherlands, 1973.

[22] Lowak, H.; deJonge, J. B.; Franz, J. and Schutz, D., "Mini-TWIST--A Shortened Version of TWIST," LBF Report No. TB-146, Laboratorium fur Betriebsfestigkeit, Germany, 1979.

[23] Edwards, P. R. and Darts, J., "Standardised Fatigue Loading Sequences for Helicopter Rotors (Helix and Felix) - Part 2: Final Definition of Helix and Felix," RAE Technical Report 84085, 1984.

[24] Hudson, C. M., "Effect of Stress Ratio on Fatigue-Crack Growth in 7075-T6 and 2024-T3 Aluminum Alloy Specimens," NASA TN D-5390, 1969.

[25] Phillips, E. P., "The Influence of Crack Closure on Fatigue Crack Growth Thresholds in 2024-T3 Aluminum Alloy," ASTM STP 982, 1988, pp. 505-515.

[26] Dubensky, R. G., "Fatigue Crack Propagation in 2024-T3 and 7075-T6 Aluminum Alloys at High Stress," NASA CR-1732, March 1971.

[27] Newman, J. C., Jr.; Wu, X. R.; Swain, M. H.; Zhao, W.; Phillips, E. P. and Ding, C. F., "Small-Crack Growth Behavior in High-Strength Aluminum Alloys - A NASA/CAE Cooperative Program," 18th Congress International Council of Aeronautical Sciences, Beijing, PRC, September 1992, pp. 799-820.

[28] Newman, J. C., Jr.; Wu, X. R.; Venneri, S. L and Li, C. G., "Small-Crack Effects in HighStrength Aluminum Alloys - A NASACAE Cooperative Program," NASA Reference Publication 1309, 1994.

[29] Swain, M. H., Everett, R. A., Newman, J. C., Jr. and Phillips, E. P., "The Growth of Short Cracks in 4340 Steel and Aluminum-Lithium 2090," AGARD R-767, P. R. Edwards and J. C. Newman, Jr., eds., 1990, pp. 7.1-7.30.

[30] Dugdale, D. S., "Yielding of Steel Sheets Containing Slits," Journal of Mechanics and Physics of Solids, Vol. 8, No. 2, 1960, pp. 100-104.

[31] Blom, A. F., Wang, G. S. and Chermahini, R. G., "Comparison of Crack Closure Results Obtained by 3-D Elastic-Plastic FEM and Modified Dugdale Model," Proceedings 1st International Conference on Computer Aided Assessment and Control of Localized Damage, Portsmouth, England, 1990, pp. 57-68.

[32] Schijve, J., "Significance of Fatigue Cracks in Micro-Range and Macro-Range," Fatigue Crack Propagation, ASTM STP 415, 1967, pp. 415-459.

[33] Newman, J. C.; Swain, M. H. and Phillips, E. P., "An Assessment of the Small-Crack Effect for 2024-T3," Small Fatigue Cracks, R. Ritchie and J. Lankford, eds., 1986, pp. 427-452. 
[34] Newman, J. C., Jr., "FASTRAN II - A Fatigue Crack Growth Structural Analysis Program," NASA TM 104159, 1992.

[35] Newman, J. C., Jr., "Effects of Constraint on Crack Growth under Aircraft Spectrum Loading," Fatigue of Aircraft Materials, A. Beukers et al., eds., Delft University Press, 1992, pp. 83-109.

[36] Newman, J. C., Jr., "Fracture Analysis of Various Cracked Configurations in Sheet and Plate Materials," ASTM STP 605, 1976, pp. 104-123.

[37] Lankford, J. , "The Growth of Small Fatigue Cracks in 7075-T6 Aluminum," Fatigue of Engineering Materials and Structures, Vol. 5, 1982, pp. 233-248.

[38] Grover, H. J.; Hyler, W. S.; Kuhn, P.; Landers, C. B. and Howell, F. M., "Axial-Load Fatigue Properties of 24S-T and 75S-T Aluminum Alloy as Determined in Several Laboratories," NACA TN-2928, 1953.

[39] Landers, C. B. and Hardrath, H. F., "Results of Axial-Load Fatigue Tests on Electropolished 2024-T3 and 7075-T6 Aluminum Alloy Sheet Specimens with Central Holes," NACA TN-3631, 1956.

[40] Bowles, C. Q. and Schijve, J., "The Role of Inclusions in Fatigue Crack Initiation in an Aluminum Alloy," International Joumal of Fracture, Vol. 9, No. 2, 1973, pp. 171-179. 


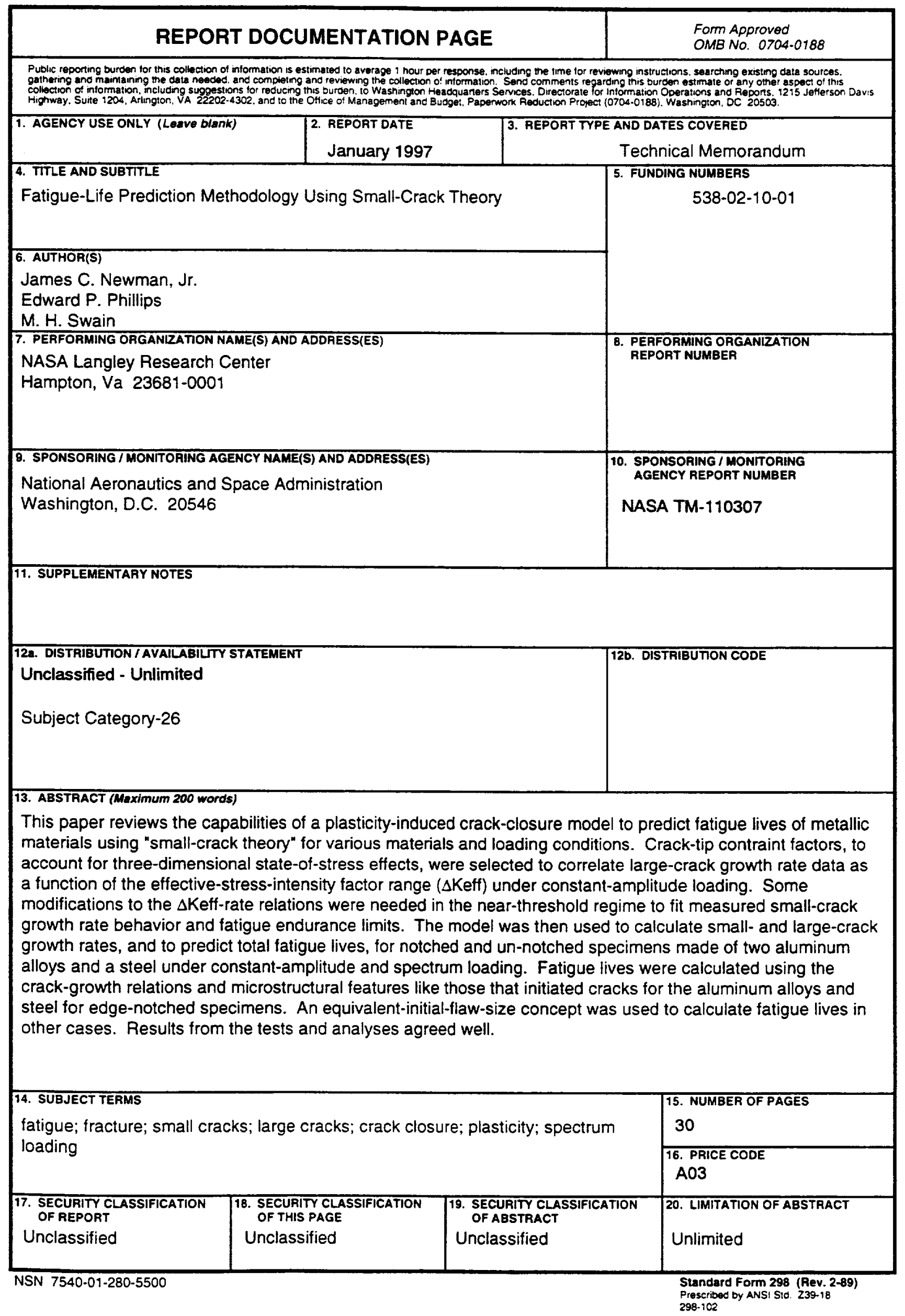

